Article

\title{
Carbon Nanotube Formation on Cr-Doped Ferrite Catalyst during Water Gas Shift Membrane Reaction: Mechanistic Implications and Extended Studies on Dry Gas Conversions
}

\author{
Xinhui Sun, Antonios Arvanitis $\mathbb{D}^{-}$, Devaiah Damma ${ }^{\mathbb{D}}$, Noe T. Alvarez, Vesselin Shanov, \\ Panagiotis G. Smirniotis and Junhang Dong * \\ Department of Chemical and Environmental Engineering, University of Cincinnati, Cincinnati, OH 45221, USA; \\ sunxh@mail.uc.edu (X.S.); arvanias@ucmail.uc.edu (A.A.); dammadh@ucmail.uc.edu (D.D.); \\ alvarene@UCMAIL.UC.EDU (N.T.A.); SHANOVVN@UCMAIL.UC.EDU (V.S.); smirnipp@ucmail.uc.edu (P.G.S.) \\ * Correspondence: junhang.dong@uc.edu
}

Received: 28 July 2020; Accepted: 10 August 2020; Published: 12 August 2020

check for updates

\begin{abstract}
A nanocrystalline chromium-doped ferrite ( $\mathrm{FeCr}$ ) catalyst was shown to coproduce $\mathrm{H}_{2}$ and multiwalled carbon nanotubes (MWCNTs) during water gas shift (WGS) reaction in a $\mathrm{H}_{2}$-permselective zeolite membrane reactor $(\mathrm{MR})$ at reaction pressures of $\sim 20$ bar. The FeCr catalyst was further demonstrated in the synthesis of highly crystalline and dimensionally uniform MWCNTs from a dry gas mixture of $\mathrm{CO}$ and $\mathrm{CH}_{4}$, which were the apparent sources for MWCNT growth in the WGS MR. In both the WGS MR and dry gas reactions, the operating temperature was $500{ }^{\circ} \mathrm{C}$, which is significantly lower than those commonly used in MWCNT production by chemical vapor deposition (CVD) method from $\mathrm{CO}, \mathrm{CH}_{4}$, or any other precursor gases. Extensive ex situ characterizations of the reaction products revealed that the $\mathrm{FeCr}$ catalyst remained in partially reduced states of $\mathrm{Fe}^{3+} / \mathrm{Fe}^{2+}$ and $\mathrm{Cr}^{6+} / \mathrm{Cr}^{3+}$ in WGS membrane reaction while further reduction of $\mathrm{Fe}^{2+}$ to $\mathrm{Fe}^{0}$ occurred in the $\mathrm{CO} / \mathrm{CH}_{4}$ dry gas environments. The formation of the metallic Fe nanoparticles or catalyst surface dramatically improved the crystallinity and dimensional uniformity of the MWCNTs from dry gas reaction as compared to that from WGS reaction in the MR. Reaction of the $\mathrm{CO} / \mathrm{CH}_{4}$ mixture containing $500 \mathrm{ppmv}$ $\mathrm{H}_{2} \mathrm{~S}$ also resulted in high-quality MWCNTs similar to those from the $\mathrm{H}_{2} \mathrm{~S}$-free feed gas, demonstrating excellent sulfur tolerance of the FeCr catalyst that is practically meaningful for utilization of biogas and cheap coal-derived syngas.
\end{abstract}

Keywords: Cr-doped ferrite; membrane reactor; water gas shift; carbon nanotubes; sulfur resistance

\section{Introduction}

The water gas shift (WGS) reaction is a key operation in the industrial production of hydrogen from fossil fuel and biomass or biogas-derived syngas. The reaction, as expressed by Equation (1), is moderately exothermic and reversible. The WGS reaction rate is enhanced but the equilibrium $\mathrm{CO}$ conversion is lowered when increasing reaction temperature.

$$
\mathrm{CO}+\mathrm{H}_{2} \mathrm{O} \stackrel{\text { cat }}{\Leftrightarrow} \mathrm{H}_{2}+\mathrm{CO}_{2}, \Delta H_{r}^{o}=-41.2 \mathrm{~kJ} / \mathrm{mol}
$$

For the past decades, the concept of high-temperature $\mathrm{H}_{2}$-permselective WGS membrane reactor (MR) has attracted tremendous interest because of its capability to overcome the limit of equilibrium conversion by instantaneously separating and removing the $\mathrm{H}_{2}$ product from the catalyst bed during reaction. The $\mathrm{H}_{2}$-permselective WGS MRs are thus widely viewed as a promising means to lower 
costs of $\mathrm{H}_{2}$ production with simultaneous $\mathrm{CO}_{2}$ separation and capture because they enable significant process intensification and simplification for the reduction of energy consumption and capital cost [1].

In the past, substantial progress has been made in developing $\mathrm{H}_{2}$-permselective membranes and WGS catalysts with hydrothermal stability and chemical resistance for processing the $\mathrm{H}_{2} \mathrm{~S}$-containing syngas from fossil fuels and biogases. The group of transition metal-doped ferrite catalysts is well known for their excellent activity in catalyzing WGS reaction at high temperatures $\left(350 \sim 550{ }^{\circ} \mathrm{C}\right)$. Various metal dopants in the ferrite catalyst have been used to enhance the kinetic rates, material stability, and tolerance to sulfur impurities in the feed gases [2]. Recently, we demonstrated a modified MFI-type zeolite membrane with long-term stability and a high $\mathrm{H}_{2} / \mathrm{H}_{2} \mathrm{~S}$ separation factor for WGS MR operation at high temperature and pressure [3,4]. The combination of the ferrite-based catalysts with the $\mathrm{H}_{2}$-permselective zeolite membrane was able to achieve near-complete $\mathrm{CO}$ conversion ( $\left.\chi_{\mathrm{CO}}>99.5 \%\right)$ under high reaction pressure $\left(>15\right.$ bar) and temperature $\left(\sim 500^{\circ} \mathrm{C}\right)$ with and without high $\mathrm{H}_{2} \mathrm{~S}$ content (>400 ppm) in the feed [5]. The high-temperature and high-pressure (HTP) conditions on the reaction side elevate the $\mathrm{H}_{2}$ partial pressure on the reaction side $\left(p_{H 2, r}\right)$ that, with near-zero $\mathrm{H}_{2}$ partial pressure on the permeate side $\left(p_{H 2, p}\right)$, maintains the driving force (i.e., $\Delta p_{H 2}=p_{H 2, r}-p_{H 2, p}$ ) for maximum removal of $\mathrm{H}_{2}$ through membrane permeation, which is necessary for approaching complete $\mathrm{CO}$ conversion [5]. In this case, the HTP reaction conditions may create extremely $\mathrm{H}_{2}$-lean gas environments that are fundamentally different from that in the conventional packed bed WGS reactors or in most of the reported WGS MRs where $\mathrm{H}_{2}$ removal is often far from completion. The HTP WGS MR operation conditions may become thermodynamically favorable for the $\mathrm{CO}$ carbonization and methanation reactions because of their volume reduction nature. Although WGS catalyst deactivation by surface coking has been known as a long-standing concern [6], carbon formation, especially the possible coproduction of valuable carbon nanomaterials on ferrite catalysts in HTP WGS MR reactions, has not been specifically investigated so far.

In the literature, Fe-based catalysts have been reported to produce graphitic carbon materials from $\mathrm{CO}$ and $\mathrm{CH}_{4}$ gases [7-10]. The structure of the carbon products can vary broadly depending on the catalyst, feed gas composition, and reaction conditions, and often includes mixtures of carbon coatings, particulates, nanofibers, and nanotubes, etc. The carbon nanotubes (CNTs) are mostly produced by CVD of high-purity $\mathrm{CO}$ or hydrocarbons using metallic nanoparticle catalysts with or without oxide supports. The biogas and coal-derived syngas, however, often contains $\mathrm{H}_{2} \mathrm{~S}$ impurities, which can poison most WGS catalysts. The sulfur resistance of the doped ferrite catalysts for high-temperature WGS membrane reaction has been well documented in our previous reports [3,11]. However, the $\mathrm{FeCr}$ catalyst surface composition and chemistry during MWCNTs formation in the strongly reducing $\mathrm{CO} / \mathrm{CH}_{4}$ dry gas can dramatically differ from that in the HTP WGS MRs, where oxidizing steam exists. Sulfur can react with metallic iron to form FeS to lower the surface energy and inhibit aggregation and sintering of catalyst nanoparticles that consequently help in maintaining good chirality and dimensional uniformity of the resultant CNTs $[12,13]$. To take advantage of such beneficial effects, trace level sulfur compounds are formed in the catalyst prior to the CVD reaction of pure gas precursors. Metal sulfates, such as $\mathrm{FeSO}_{4}, \mathrm{NiSO}_{4}$, and $\mathrm{CoSO}_{4}$, have been used as precursor to form sulfur-containing catalysts for CNT synthesis [13-16]. The sulfur contents in the catalyst surface were often not detectable by common characterization methods, such as energy dispersive X-ray spectroscopy (EDS) with scanning electron microscopy (SEM), transmission electron microscopy (TEM), and X-ray photoelectron spectroscopy (XPS), because of their trace amounts. Although trace FeS alloy in the metallic catalysts may facilitate CNT formation, excessive sulfur contents could adversely affect the catalytic activity. Therefore, the effects of $\mathrm{H}_{2} \mathrm{~S}$ impurity in the continuously fed gas flow and possible accumulative incorporation of sulfur into the originally sulfur-free catalyst on carbon formation during the CVD reactions of $\mathrm{CO}$ and $\mathrm{CH}_{4}$ gases can be different and are currently not clear.

In this work, a Cr-doped ferrite ( $\mathrm{FeCr}$ ) nanocrystalline catalyst has been investigated for catalyzing MWCNT formation in a $\mathrm{H}_{2}$-permselective MFI-type zeolite MR under HTP WGS membrane reaction conditions, where near-complete $\mathrm{CO}$ conversion is achieved by virtually total removal of $\mathrm{H}_{2}$ product. 
The FeCr catalysts are one of the most established HTP WGS catalyst with the Cr-dopant known to reduce the crystallite size and prevent nanoparticle sintering for long-term stabilization $[17,18]$. Based on the findings of the HTP WGS MR reactions, extended studies are carried out on the reactions of the $\mathrm{FeCr}$ catalyst with dry gases containing $\mathrm{CO}$ and $\mathrm{CH}_{4}$, which are apparent sources in the WGS MR for direct carbonization on $\mathrm{FeCr}$ oxide surfaces. Experiments are also conducted for the $\mathrm{CO} / \mathrm{CH}_{4}$ dry gas containing a high content of $\mathrm{H}_{2} \mathrm{~S}$ that is practically important for the potential utilization of biogas and cheap coal-derived syngas.

\section{Results and Discussion}

\subsection{MWCNT Formation in WGS MR}

The WGS reaction was carried out in the $\mathrm{FeCr}$ catalyst-packed MR at $500{ }^{\circ} \mathrm{C}$ as a function of time and reaction side pressure, and the results are presented in Figure 1. The $\chi_{\mathrm{CO}}$ of the MR increased continuously with reaction side pressure while the permeate side sweep flow remained at atmospheric pressure. Such a $\chi_{\mathrm{CO}}$ dependency on the reaction pressure can be attributed to the prolonged residence time, accelerated reaction rate, and enhanced $\mathrm{H}_{2}$ membrane permeation rate under increased reaction pressures at a fixed gas hourly space velocity (GHSV) [4,5]. At GHSV $=7500 \mathrm{~h}^{-1}$ and steam-to-CO ratio $R_{S / C O}=3.5$, the MR achieved CO conversion $\chi_{C O}>99.5 \%$ when operating at reaction side exiting pressure $P_{r, e x}$ of $>15$ bar. As can be seen in Figure 1a,b, near-complete CO conversion was obtained with almost total hydrogen recovery $R_{\mathrm{H}_{2}}(\sim 99 \%)$ at a cost of significantly lowered $\mathrm{H}_{2}$ concentration in the permeate $\left(\mathrm{y}_{\mathrm{H}_{2}}\right)$ due to the membrane's limited $\mathrm{H}_{2} / \mathrm{CO}_{2}$ selectivity $\alpha_{\mathrm{H} 2 / \mathrm{CO} 2} \sim 25$. During the MR operation, the $P_{r, e x}$ was maintained at each preset value while the pressure of feed entrance $\left(P_{r, i n}\right)$ was elevated to keep the GHSV constant when the resistance to gas flow in the catalyst bed increased continually by the accumulating carbon deposits. Figure 1a shows that $P_{r, e x}$ was able to stabilize to below 15 bar without large adjustments for $P_{r, i n}$, indicating that carbon deposition was insignificant or very slow under relatively low reaction pressures, which is consistent with the findings on similar Cr-doped ferrite catalysts $[5,11]$. However, when the $P_{r, e x}$ reached 20 bar, where $\chi_{\text {CO }}$ exceeded $99.5 \%$ at $R_{\mathrm{H}_{2}}$ of $\sim 99 \%$, the $P_{r, \text { in }}$ rapidly increased in order to keep GHSV unchanged. The MR operation was terminated at $P_{r, i n}$ of $\sim 30$ bar around which the GHSV was no longer able to stabilize as the tube side catalyst bed became tightly clogged by the accumulated carbon deposits; meanwhile, shortly after reaching $\chi_{C O}>99.5 \%$ at $P_{r, e x}$ of $>15$ bar, the $\chi_{C O}$ started to drop sharply with time because of severe catalyst deactivation by carbon coverage. The fast decline of $\chi_{\mathrm{CO}}$ occurred similarly for feeds of higher GHSV (e.g., 15,000 and $30,000 \mathrm{~h}^{-1}$ ) and/or lower $R_{S / C O}$ (e.g., 1.5) when the MR was operated at $500{ }^{\circ} \mathrm{C}$ and 20 bar (see Figure S1). The $\chi_{C O}$ of the WGS MR was able to reach $>99.5 \%$ at GHSV $=15,000 \mathrm{~h}^{-1}$ and $R_{S / C O}=3.5$ but not for GHSV $=30,000 \mathrm{~h}^{-1}$ with $R_{S / C O}=3.5$ or for GHSV $=15,000 \mathrm{~h}^{-1}$ with $R_{S / C O}=1.5$ because of shortened residence time at greater GHSV $\left(=30,000 \mathrm{~h}^{-1}\right)$ or lowered equilibrium CO conversion for the smaller $R_{S / C O}(=1.5)$. 


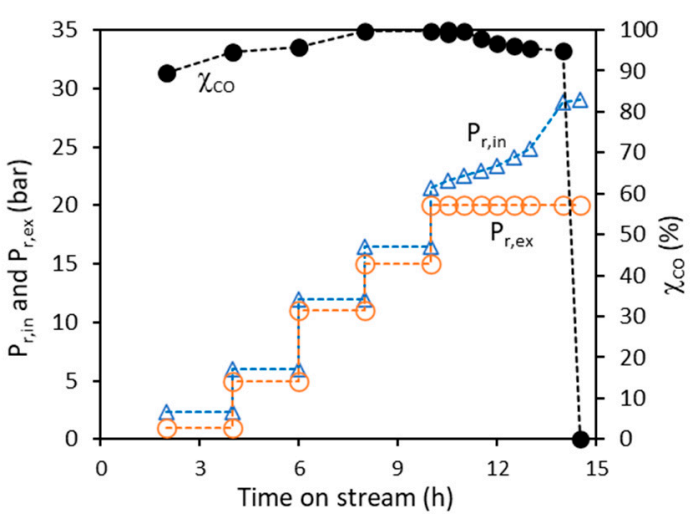

(a)

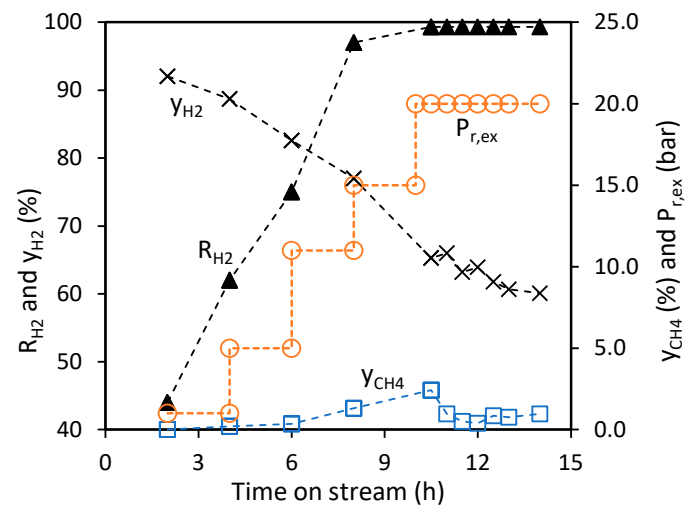

(b)

Figure 1. Results of WGS reaction at $500{ }^{\circ} \mathrm{C}$ in the zeolite MR as a function of time-on-stream with correspondingly increasing reaction pressure and constant atmospheric pressure on the permeate side: (a) $\chi_{\mathrm{CO}}$ and corresponding $P_{r, i n}$ and $P_{r, e x}$, and (b) $R_{\mathrm{H} 2}$ and $\mathrm{y}_{\mathrm{H}_{2}}$ in permeate and $\mathrm{y}_{\mathrm{CH} 4}$ in retentate.

In Figure $1 \mathrm{~b}$, the dry gas-based mole fraction of the byproduct $\mathrm{CH}_{4}$ in the reaction side $\left(y_{\mathrm{CH}}\right)$ was quite low $\left(y_{\mathrm{CH} 4}<2.5 \%\right)$ but increased monotonically with the rising reaction pressure up to $\sim 20$ bar. The $\mathrm{CH}_{4}$ was virtually undetectable in the permeate stream because of its very small permeation rate. This pressure dependency of $y_{\mathrm{CH} 4}$ in the MR may be explained by the fact that the methanation increases with pressure because of the volume reduction reactions and, on the other hand, methanation is mitigated by timely removal of the produced $\mathrm{H}_{2}$, which is a precursor for $\mathrm{CH}_{4}$. Immediately after $\chi_{\mathrm{CO}}$ reached near-completion (>99.5\%) at $20 \mathrm{bar}$, the $y_{\mathrm{CH} 4}$ exhibited a trend of decreasing and then slightly increasing with operation time. Such a drop of methanation rate was also observed in other WGS MR reaction conditions in Figure S1, though the subsequent increase of $y_{\mathrm{CH} 4}$ after the initial drop at 20 bar was not always appreciable likely because of the fast carbon deposition rate at 20 bar that led to fluctuation of gas flowrate and consequently large deviations in determining the $y_{\mathrm{CH} 4}$. Nevertheless, the unique $y_{\mathrm{CH} 4}$ dependency on operation time and reaction pressure indicate the involvement of $\mathrm{CH}_{4}$ or chemisorbed intermediates (e.g., surface $\mathrm{CH}_{x}, 0 \leq x<4[19,20]$ ) in carbon formation during HTP WGS reaction in the MR.

Structures of the carbon products. After terminating the WGS reaction upon the rapid $P_{r, \text { in }}$ increase, the MR was cooled down in a continued $\mathrm{N}_{2}$ purging gas flow, and the membrane tube was carefully opened to observe the status of the packed bed along the tube. A highly compacted carbon/catalyst bed segment was found in the first half of the active membrane section, with the other half near the exit also filled with carbon materials but less tightly packed. The solid materials of the catalyst bed were quickly retrieved and sealed in glass vials, within $20 \mathrm{~min}$, for various tests to identify the types of carbon and characterize the properties of both the catalyst and carbon products.

The SEM image in Figure 2a shows that the solid product was CNTs with lengths of a few microns and diameters in a broad range from $\sim 10$ to over $50 \mathrm{~nm}$. The results of Raman shift characterization shown in Figure $2 \mathrm{~b}$ indicate a $\mathrm{D} / \mathrm{G}$ intensity ratio $\left(\mathrm{I}_{\mathrm{D}} / \mathrm{I}_{\mathrm{G}} \sim 1.03\right)$ of the carbon materials that was typical to the MWCNTs synthesized by oxide catalyst via the CVD method. The TEM images in Figure 2c reveal that the carbon products were MWCNTs with wall thickness and graphene layer structure that are also similar to those formed on oxide catalysts, which are generally of low chirality and crystallinity and short length. The TEM image in the insert of Figure $2 \mathrm{c}$ suggested a tip-growth mechanism for the MWCNTs on the FeCr oxide catalyst. The MWCNTs, in this case, grew in the free end, i.e., tip growth mode, and the diameter was apparently defined by the catalyst particle size as shown by the SEM and TEM images in Figure S2. The composition of the MWCNTs measured by the EDS technique had a $\mathrm{C} /(\mathrm{FeCr})$ atomic ratio of $\sim 119$ and a mass ratio of $\sim 70$ assuming that the catalyst had a partially reduced state of $\mathrm{Fe}_{3} \mathrm{O}_{4}$. The element $\mathrm{Cr}$ was hardly seen in the EDS spectrum in Figure 2d, likely because of its overall extremely low content in the sample of largely carbon contents. 


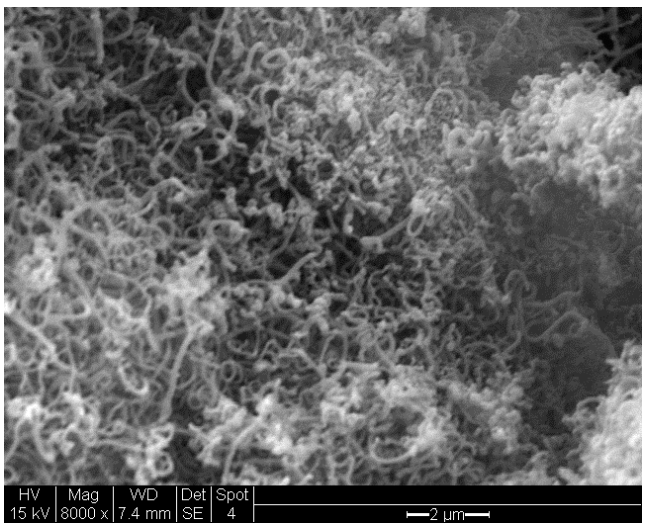

(a)

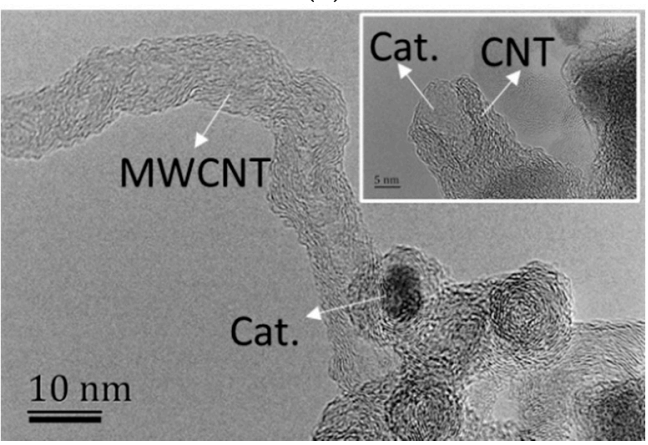

(c)

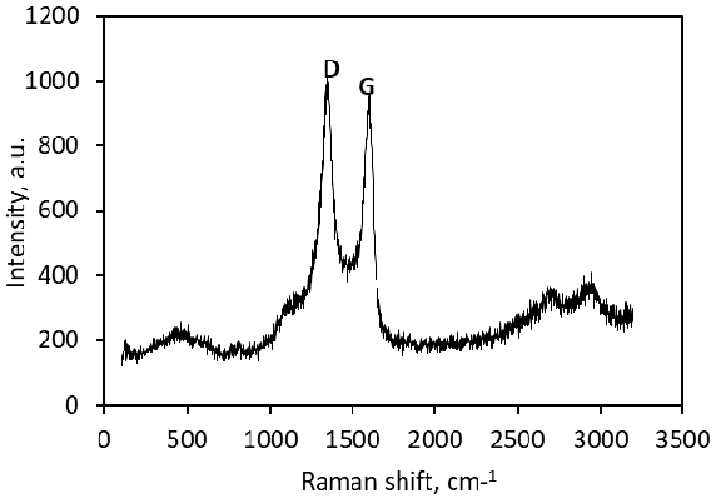

(b)

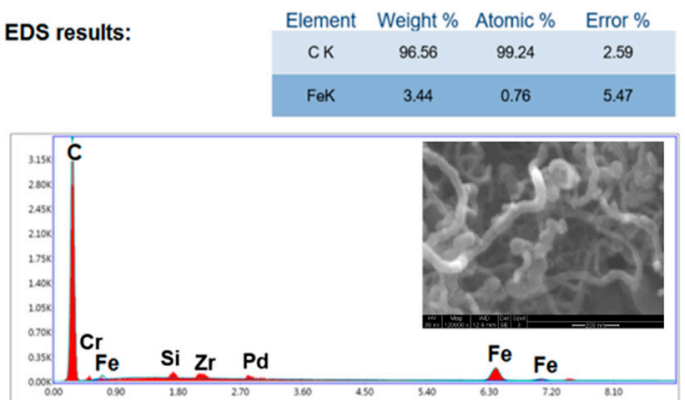

(d)

Figure 2. Characterizations for the carbon/catalyst materials formed in the HTP WGS MR: (a) SEM image, (b) Raman shift, (c) TEM image, and (d) SEM-EDS results.

States of the catalysts. The mechanisms of CNT tip-growth on oxide and metallic particles are different with the former depending on surface chemisorption followed by surface migration of carbonaceous intermediates, and for the latter, involving carbon dissolution as metal carbides and diffusion through metallic body to supply the CNT growth [21,22]. The oxidation states of the metal elements in FeCr catalysts were examined using the XPS technique for samples in different stages of processing. The XPS investigation was also used to provide evidence for the involvement of $\mathrm{CO}$ and $\mathrm{CH}_{4}$ in catalytic carbon formation on the catalyst. Figure 3 displays the XPS spectra for catalyst samples including (1) the as-synthesized FeCr catalyst denoted as "Fresh FeCr", (2) the catalyst after activation in the reducing process gas denoted as "Reduced $\mathrm{FeCr}^{\prime}$ ", (3) catalyst after WGS reaction in the MR denoted as "Reacted FeCr", and (4) a catalyst containing no Cr dopant named as "Reacted FeOx", which was similarly activated and treated by WGS reaction processes to provide a reference. 


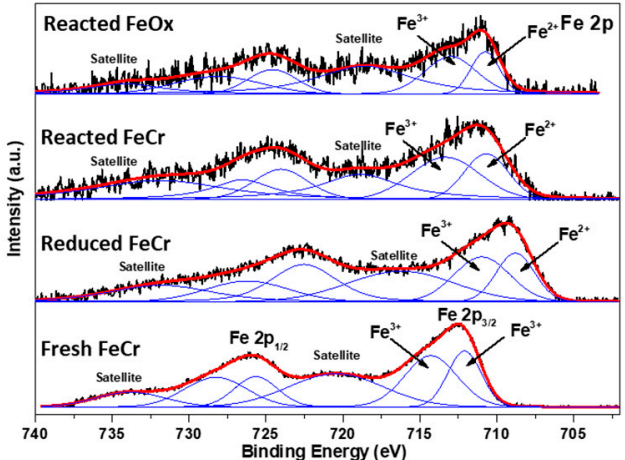

(a)

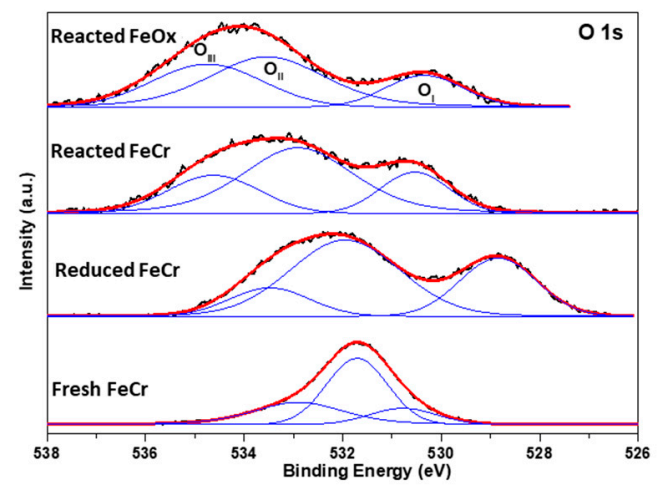

(c)

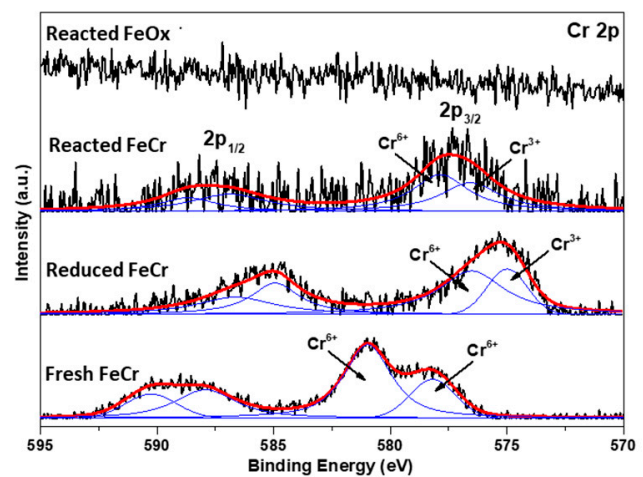

(b)

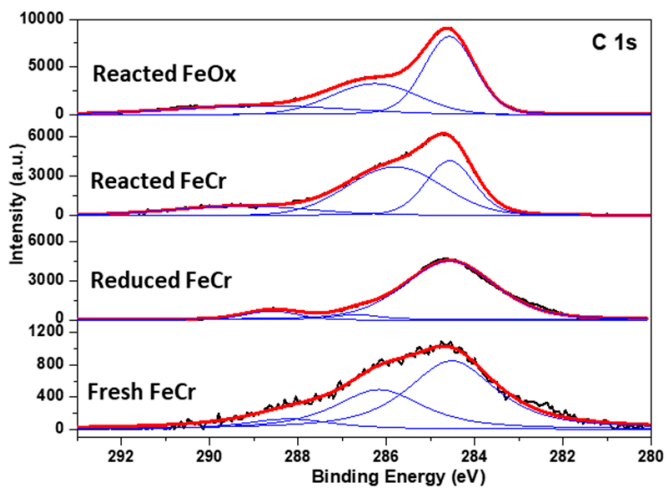

(d)

Figure 3. XPS spectra of the FeCr catalyst samples at various stages of processing: (a) the Fe 2p XPS spectra, (b) the Cr 2p core-level XPS spectra, (c) the O 1s spectra, and (d) the C 1s spectra.

In Figure 3a, the Fe 2p XPS spectrum of the fresh FeCr contains two distinct peaks at $712.5 \mathrm{eV}$ for $\mathrm{Fe} 2 \mathrm{p}_{3 / 2}$ and at $725.9 \mathrm{eV}$ for Fe $2 \mathrm{p}_{1 / 2}$ along with two satellites at 720.4 and $734.0 \mathrm{eV}$ that indicate the presence of $\alpha-\mathrm{Fe}_{2} \mathrm{O}_{3}$ phase in the sample. Although the reduced and reacted catalysts exhibited similar peaks like in the fresh sample, the binding energies of the $\mathrm{Fe} 2 \mathrm{p}_{3 / 2}, \mathrm{Fe} 2 \mathrm{p}_{1 / 2}$, and satellite bands were shifted to lower values. These shifts can be attributed to the formation of $\mathrm{Fe}_{3} \mathrm{O}_{4}$ phase in the reduced and reacted $\mathrm{FeCr}$ catalysts. Further, the Fe $2 \mathrm{p}$ spectra were deconvoluted using the Gaussian-Lorentzian line shape and the fitted results show that the peak of Fe $2 p_{3 / 2}$ and Fe $2 p_{1 / 2}$ core-level electrons split into two components in all the catalysts. In particular, the fitted peaks of Fe $2 p_{3 / 2}$ indicate the presence of mixed $\mathrm{Fe}^{3+/ 2+}$ valence states in the reduced and reacted catalysts but not in the fresh sample. This confirms pure $\mathrm{Fe}_{2} \mathrm{O}_{3}$ phase for the fresh catalyst and the existence of $\mathrm{Fe}_{3} \mathrm{O}_{4}$ phase in the reduced and reacted samples. The Fe $2 p_{3 / 2}$ envelope does not show any appreciable peak at around $708 \mathrm{eV}$, indicating the absence of metallic $\mathrm{Fe}\left(\mathrm{Fe}^{0}\right)$. Figure $3 \mathrm{~b}$ presents the $\mathrm{Cr} 2 \mathrm{p}$ core-level XPS spectra of $\mathrm{FeCr}$ catalysts in contrast to the $\mathrm{Cr}$-free sample of $\mathrm{FeOx}$, which has no peaks in the $\mathrm{Cr} 2 \mathrm{p}$ region. In the spectra of the $\mathrm{FeCr}$ samples, the spin-orbit splitting of the XPS spectra shows a double $2 \mathrm{p}_{1 / 2}$ and $2 \mathrm{p}_{3 / 2}$ excitations. The fitted $\mathrm{Cr} 2 \mathrm{p}_{3 / 2}$ spectrum of fresh catalyst exhibits peaks at about 580.9 and $578.1 \mathrm{eV}$, which are assigned to the $\mathrm{Cr}^{6+}$ species. On the other hand, the deconvoluted $\mathrm{Cr}$ $2 p_{3 / 2}$ spectra of reduced and reacted $\mathrm{FeCr}$ catalysts indicate the presence of both $\mathrm{Cr}^{6+}$ and $\mathrm{Cr}^{3+}$ states. Moreover, the binding energy of the reduced and reacted samples was blue-shifted from that of the fresh sample. This could be due to the existence of more $\mathrm{Cr}^{6+}$ species in the fresh catalyst that have higher electronegativity than the $\mathrm{Cr}^{3+}$ species.

The deconvoluted $\mathrm{O} 1 \mathrm{~s}$ spectra of all samples exhibited three peaks in Figure 3c, which are assigned as $\mathrm{O}_{\mathrm{I}}, \mathrm{O}_{\mathrm{II}}$, and $\mathrm{O}_{\mathrm{III}}$. The $\mathrm{O}_{\mathrm{I}}$ peak is ascribed to the lattice oxygen, while the $\mathrm{O}_{\mathrm{II}}$ and $\mathrm{O}_{\mathrm{III}}$ bands respectively correspond to the surface-adsorbed oxygen species and weakly bonded oxygen species, like molecular water or carbonate species, on the catalysts. The $C 1$ s spectrum is usually 
expected from the background carbon tape used during the XPS analysis. However, the intensities of the $C 1$ s peaks from the reduced and reacted catalysts in Figure $3 \mathrm{~d}$ were far greater than that of the fresh sample, which only exhibits weak background carbon peaks. The dramatic change of $C 1 \mathrm{~s}$ peak intensity is indicative of carbon formation during the activation (reduction) and WGS reaction processes. Moreover, the reacted catalysts exhibited the highest $C 1$ s peak intensity that suggests more carbon formed on the surface as compared to the reduced sample. The fitted $C 1 \mathrm{~s} \mathrm{spectra}$ of the samples show the peaks at 284.6, 285.6-286.8, and 288.3-289.6 eV, which can be attributed to C-C and/or $\mathrm{C}-\mathrm{H}$ bonds, carbon linked to one $\mathrm{O}$ atom by a single bond $(\mathrm{C}-\mathrm{OH}, \mathrm{C}-\mathrm{O}-\mathrm{C}, \mathrm{C}-\mathrm{O}-\mathrm{R})$ or a double bond $(-\mathrm{C}=\mathrm{O})$, and carbon attached to two oxygen atoms $(-\mathrm{COOH})$, respectively.

The above XPS analyses of the $\mathrm{FeCr}$ catalysts at different processing states indicate that the $\mathrm{Fe}^{3+}$ and $\mathrm{Cr}^{6+}$ were partially reduced to $\mathrm{Fe}^{2+}$ and $\mathrm{Cr}^{3+}$ to form $\mathrm{Cr}$-doped ferrite $\left(\mathrm{Fe}_{3} \mathrm{O}_{4}\right)$ after being activated in the reducing gas flow. The XPS spectra of the solid products from the WGS membrane reaction revealed $\mathrm{C}-\mathrm{C}$ and $\mathrm{C}-\mathrm{H}$ bonds formed in the surface carbonaceous species and $\mathrm{O}-\mathrm{C}$ and $\mathrm{O}-\mathrm{CH}_{x}$ in the catalyst surface. These carbonaceous species are common intermediates of nonoxidative dehydrogenation of $\mathrm{CH}_{4}$ on oxide-promoted metal catalysts [20]. It is evident that during the WGS $\mathrm{MR}$ reaction, carbon formation from both $\mathrm{CO}$ and $\mathrm{CH}_{4}$ or methanation intermediates occurred in the catalyst surface under $\mathrm{H}_{2}$-lean HTP conditions. However, it is not clear whether the two apparent carbon sources, namely $\mathrm{CO}$ and $\mathrm{CH}_{4}$, had synergistic or interdependent effects in MWCNT growth on the catalyst surface. The XPS and TEM results showed no direct evidence of metallic elements, suggesting that the limited reducing power of gases containing high-concentration steam and $\mathrm{CO}_{2}$, which are weakly oxidative, is unable to further reduce the $\mathrm{Fe}^{2+}$ to $\mathrm{Fe}^{0}$.

\subsection{Reaction of Dry Source Gases on FeCr Catalysts}

The chemical analyses of the gas products and XPS examinations of the solid products from the HTP WGS membrane reaction have suggested the involvements of CO disproportionation, Reaction (2), and $\mathrm{CH}_{4}$ dehydrogenation, Reaction (3), in MWCNT growth on the FeCr catalyst.

$$
\begin{aligned}
& 2 \mathrm{CO} \stackrel{\text { cat. }}{\leftrightarrow} \mathrm{CO}_{2}+\mathrm{C}, \Delta H_{r}^{o}=-173 \mathrm{~kJ} / \mathrm{mol} \\
& \mathrm{CH}_{4} \stackrel{\text { cat. }}{\leftrightarrow} \mathrm{C}+2 \mathrm{H}_{2}, \Delta H_{r}^{o}=+74.9 \mathrm{~kJ} / \mathrm{mol}
\end{aligned}
$$

Reaction (2) is favored at high pressure by its volume reduction effect. Reaction (3) is, however, a volume increase process but can be facilitated by instantly removing the product $\mathrm{H}_{2}$ from the catalyst through selective membrane permeation. On the other hand, the removal of $\mathrm{H}_{2}$ from the catalyst zone could inhibit the methanation processes, which could include the following reactions [4,23]:

$$
\begin{gathered}
\mathrm{CO}+3 \mathrm{H}_{2} \stackrel{\text { cat. }}{\leftrightarrow} \mathrm{CH}_{4}+\mathrm{H}_{2} \mathrm{O}, H_{r}^{o}=-206 \mathrm{~kJ} / \mathrm{mol} \\
\mathrm{CO}_{2}+4 \mathrm{H}_{2} \stackrel{\text { cat. }}{\leftrightarrow} \mathrm{CH}_{4}+2 \mathrm{H}_{2} \mathrm{O}, H_{r}^{o}=-164 \mathrm{~kJ} / \mathrm{mol}
\end{gathered}
$$

The rapid decline of $\mathrm{CH}_{4}$ content upon carbon formation in the WGS MR at 20 bar, as shown in Figure $1 \mathrm{~b}$ and Figure S1, may be attributed to sudden catalyst deactivation by the fast carbon deposits. Although the catalytic methane decomposition could involve complicated serial reaction steps [24], the whole process of carbonization via the routes of methanation and $\mathrm{CH}_{4}$ decomposition must have overall stoichiometric mass balance and overall energy effect the same as the CO disproportionation Reaction (2) when WGS Reaction (1) is the $\mathrm{H}_{2}$ source for Reactions (4) and (5).

Experiments on the feeds of $\mathrm{CO}$ and $\mathrm{CH}_{4}$ single gas, a mixture containing $80 \mathrm{v} . \% \mathrm{CO}$ and $20 \mathrm{v} . \%$ $\mathrm{CH}_{4}$, and the $\mathrm{CO} / \mathrm{CH}_{4}$ gas mixture containing $500 \mathrm{ppmv} \mathrm{H}_{2} \mathrm{~S}$ were conducted to investigate the $\mathrm{FeCr}$ catalytic activities in these conditions. The $\mathrm{CO} / \mathrm{CH}_{4}$ mixture composition of $80 \mathrm{v} . \% \mathrm{CO}$ was selected because the pre-membrane catalyst bed together with the long stainless steel tubing (with oxidized surface) was able to achieve a $\chi_{C O}$ of $78 \%-86 \%$ when operating at $500{ }^{\circ} \mathrm{C}$ with $P_{r, e x}$ of $15-20$ bar, GHSV 
of $7500 \mathrm{~h}^{-1}$, and $R_{S / C O}$ of 3.5. This conversion would lead to a CO partial pressure of $\sim 0.8$ bar at the beginning of the membrane section. The $20 \mathrm{v} . \%$ of $\mathrm{CH}_{4}$ was selected largely for balancing the binary mixture at ambient total pressure within the range of $\mathrm{CH}_{4}$ partial pressures observed in the MR retentates. A total of $0.5 \mathrm{~g} \mathrm{FeCr}$ catalyst was loaded uniformly along the tube length and activated in the same process gas flow as that used in catalyst activation for WGS MR reaction.

\subsubsection{Pure CO Feed}

The reaction of pure $\mathrm{CO}$ feed was performed at $500{ }^{\circ} \mathrm{C}$ when the reaction (feed) pressure was increased from 1 bar to $\sim 22$ bar and the exiting gas flowrate was maintained at $\sim 5 \mathrm{~cm}^{3} \mathrm{STP} / \mathrm{min}$. The exiting gas composition was analyzed for estimating the $\mathrm{CO}$ conversion assuming that $\mathrm{CO}$ disproportionation was the only reaction. The GC measurement of the exiting gas composition was taken twice at each pressure, and the two measurements were about $1 \mathrm{~h}$ apart to determine the stability and consistency of the operation. A rapid decrease in $\mathrm{CO}$ conversion was observed when the reaction pressure exceeded 4.7 bar below which the $\mathrm{CO}$ conversion rate was stable, as shown in Figure S3a. Furthermore, the carbon products obtained below 4.7 bar, e.g., those obtained at $~ 1.0$ bar, were primarily graphitic carbon coatings and particles, as shown in Figure S3b-e without CNTs. An experiment on the pure $\mathrm{CO}$ reaction was then conducted at $500{ }^{\circ} \mathrm{C}$ under reaction pressure of $5.1 \mathrm{bar}$ with a feed flowrate of $\sim 10 \mathrm{~cm}^{3} \mathrm{STP} / \mathrm{min}$. The results are presented in Figure 4 . The CO conversion $\chi_{\mathrm{CO}}$ was high but constantly declining with time (Figure $4 \mathrm{a}$ ) apparently due to catalyst deactivation by increasing surface carbon coverage. The SEM and TEM results in Figure 4b show long MWCNTs grown on the FeCr catalyst particles with uniform diameters of $25-50 \mathrm{~nm}$ and wall thickness of 5-6 nm (insert in Figure 4b). The Raman shift spectrum in Figure 4c confirms that MWCNTs are of well-defined graphitic phase.

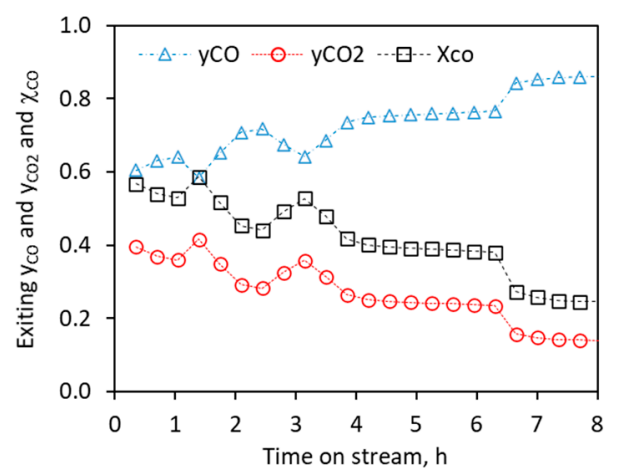

(a)

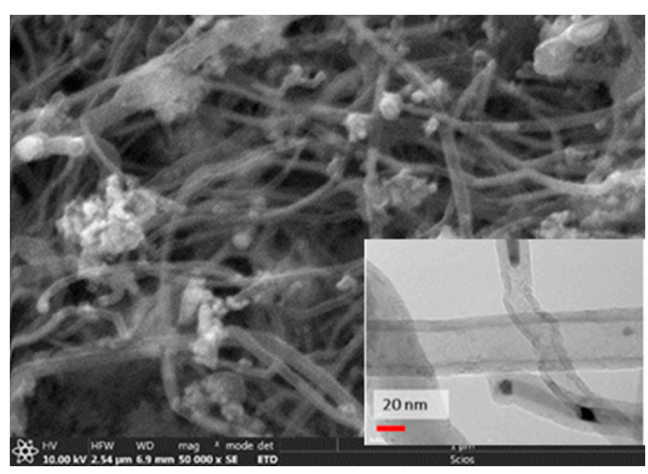

(b)

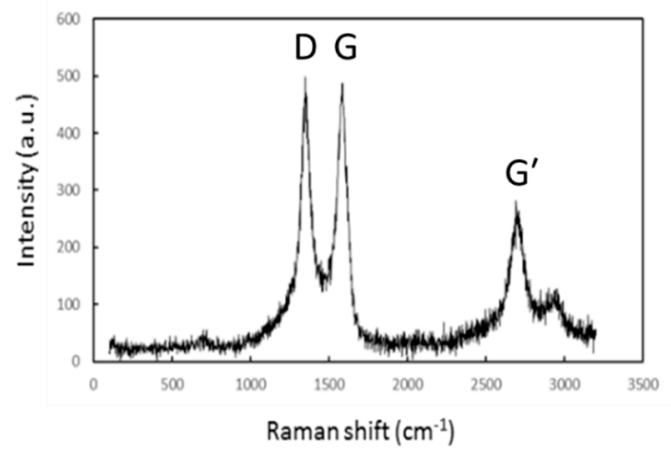

(c)

Figure 4. Results of MWCNT growth by CO reaction on the FeCr catalyst at $500{ }^{\circ} \mathrm{C}$ and 5.1 bar: (a) $\mathrm{CO}$ conversion and gas product composition as a function of reaction time, (b) SEM and TEM (insert) images of the MWCNTs, and (c) Raman shift spectrum of the produced MWCNTs. 


\subsubsection{Pure $\mathrm{CH}_{4}$ Fee}

For the $\mathrm{CH}_{4}$ single gas feed, the reaction was first performed at $500{ }^{\circ} \mathrm{C}$ and 1 bar of total pressure. The feed $\mathrm{CH}_{4}$ was carried in inert $\mathrm{N}_{2}$ and the $\mathrm{CH}_{4}$ partial pressure was changed by varying the $\mathrm{CH}_{4}$ mole fraction in the $\mathrm{CH}_{4} / \mathrm{N}_{2}$ feed, and the feed gas flowrate was maintained at $\sim 5 \mathrm{~cm}^{3} \mathrm{STP} / \mathrm{min}$. The compositions of $\mathrm{CH}_{4}$ and $\mathrm{H}_{2}$ in the gas product was monitored to estimate the $\mathrm{CH}_{4}$ conversion. The GC measurement was performed twice for each $\mathrm{CH}_{4}$ feed partial pressure over a period of $1 \mathrm{~h}$ after a stabilization period of at least $1 \mathrm{~h}$. Figure 5a presents the $\mathrm{CH}_{4}$ conversion as a function of $\mathrm{CH}_{4}$ partial pressure in the feed. The $\mathrm{CH}_{4}$ conversion was low and decreasing with increasing $\mathrm{CH}_{4}$ feed concentration until the $\mathrm{CH}_{4}$ partial pressure reached $\sim 0.5$ bar, above which the conversion remained virtually unchanged. The decrease of $\mathrm{CH}_{4}$ conversion with feed pressure may be attributed to the reaction's volume increase effect and gradual catalyst deactivation by carbon coating. The gas flowrate was stable without adjusting the feed entering pressure even after a week of operation because of the very small amount of carbon deposition, which did not cause significant clogging of the catalyst bed. The SEM image of the solid products in Figure 5b shows no appreciable MWCNTs, and the EDS result in Figure $5 c$ confirms a large amount of carbon materials on the FeCr catalyst. The peaks of Raman shift at small wavenumbers in Figure $5 \mathrm{~d}$ suggest the existence of very small graphitic structures, but the peaks around $1500 \mathrm{~cm}^{-1}$ for the MWCNTs are hardly seen because of the lack of MWCNT products. An additional experiment was also conducted for pure $\mathrm{CH}_{4}$ gas reaction with $\mathrm{CH}_{4}$ pressure up to 5 bar under which the $\mathrm{CH}_{4}$ conversion was also $<0.5 \%$ with no MWCNTs. MWCNT formation by CVD decomposition of $\mathrm{CH}_{4}$ on $\mathrm{Fe}$ catalysts has been reported at a higher temperature (e.g., $800{ }^{\circ} \mathrm{C}$ [25]) but clearly not at a low temperature $\left(500{ }^{\circ} \mathrm{C}\right)$ for the $\mathrm{FeCr}$ catalyst. These results strongly suggest that $\mathrm{CH}_{4}$ decomposition is very limited at such a low temperature and, thus, $\mathrm{CH}_{4}$ was unlikely a main source for the fast MWCNT growth in the WGS MR.

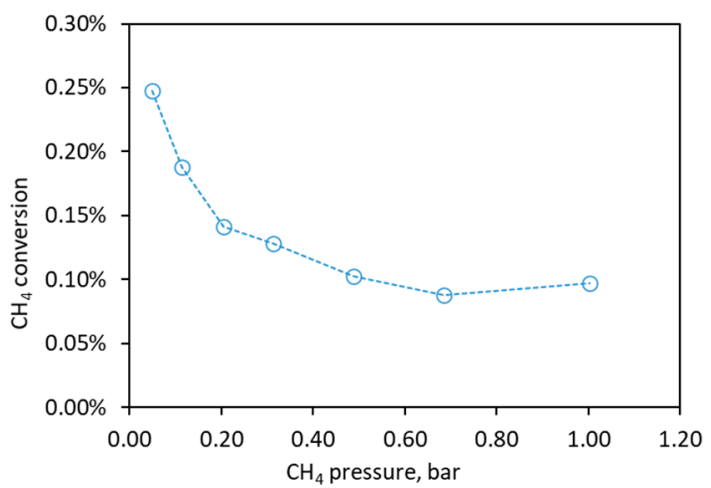

(a)

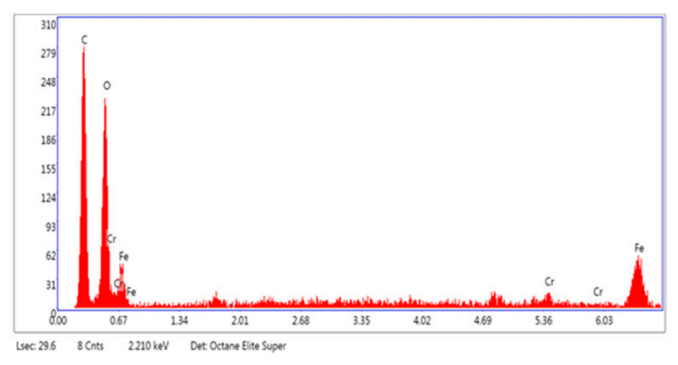

(c)

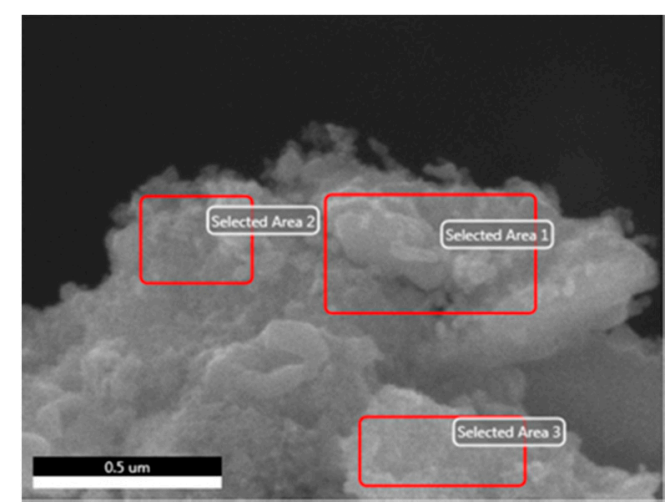

(b)

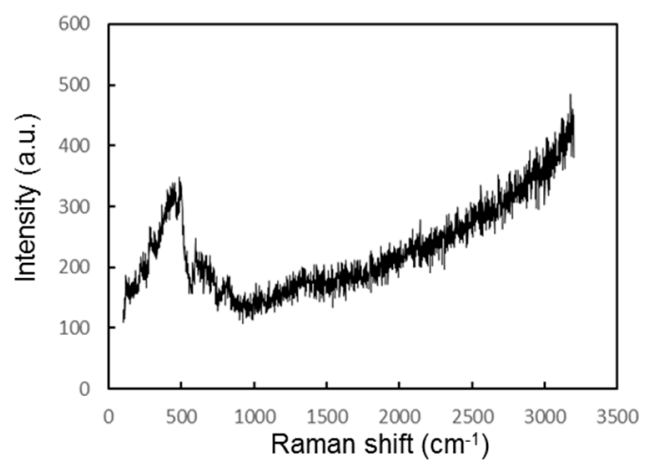

(d)

Figure 5. Results of pure $\mathrm{CH}_{4}$ reaction on the FrCr catalyst: (a) $\mathrm{CH}_{4}$ conversion as a function of feed $\mathrm{CH}_{4}$ partial pressure, (b) SEM of the solid products, (c) the EDS elemental survey, and (d) the Raman shift spectrum for the carbon products. 


\section{3. $\mathrm{CO} / \mathrm{CH}_{4}$ Mixture Reaction and Effects of $\mathrm{H}_{2} \mathrm{~S}$}

\subsection{1. $\mathrm{CO} / \mathrm{CH}_{4}$ Mixture Feed}

For the feed of $80 \mathrm{v} . \% \mathrm{CO}+20 \mathrm{v} . \% \mathrm{CH}_{4}$ gas mixture, the experiments were performed at a feed flowrate of $\sim 15 \mathrm{~cm}^{3} \mathrm{STP} / \mathrm{min}$ when the reactor inlet and exit pressures were maintained at $\sim 1.2 \mathrm{bar}$ and atmospheric pressure ( $1.013 \mathrm{bar})$, respectively. The reaction temperature was $500{ }^{\circ} \mathrm{C}$, which was markedly lower than those required for CNT production by CVD on metallic catalysts from either of the single gases or the mixtures by $[7,26-28]$. The carbon deposition was found to be very fast and only one sample of the gas product could be analyzed after $\sim 25 \mathrm{~min}$ of reaction when the drop in gas flowrate by carbon blocking was less than $30 \%$. The reaction experiment was repeated three times, and the results were reasonably consistent in terms of the fast carbon formation, MWCNT morphology, and feed gas conversion. The molar compositions of $\mathrm{CO}$ and $\mathrm{CH}_{4}$ in the gas product were $43.9 \%$ and $23.0 \%$, respectively, that is reasonably consistent with the $\sim 29.0 \% \mathrm{CO}_{2}$ and $4.1 \% \mathrm{H}_{2}$ according to the stoichiometric relations of possible reactions (2) and (3). The CO conversion was $\sim 29.0 \%$ and $\mathrm{CH}_{4}$ conversion was $\sim 9.1 \%$ by calculations based on the $\mathrm{CO}$ and $\mathrm{CH}_{4}$ composition changes. The gas flowrate started to decline sharply with time after just 30-40 min of reaction because of the fast growth of MWCNTs that blocked the catalyst-packed tube. The reaction was terminated at $1.5 \mathrm{~h}$ when the catalyst bed was severely blocked, and the gas flowrate dropped to below $3 \mathrm{~cm}^{3} \mathrm{STP} / \mathrm{min}$ even when the entering feed pressure was increased to $>3.5$ bar. The ability of $\mathrm{CO} / \mathrm{CH}_{4}$ mixture to form $\mathrm{CNTs}$ with faster kinetic rates and higher conversions than the single gas feeds was previously observed in the literature and attributed to reactions (2) and (3) but at much higher reaction temperatures $\left(>700^{\circ} \mathrm{C}\right)$ [28]. The reaction Gibbs free energy $\left(\Delta \mathrm{G}_{\mathrm{r}}\right)$ of the exothermic $\mathrm{CO}$ disproportionation increases and that of the $\mathrm{CH}_{4}$ decomposition decreases with increasing temperature with $\Delta \mathrm{G}_{\mathrm{r}}=-28 \mathrm{~kJ} / \mathrm{mol}$ for the former and $\Delta \mathrm{G}_{\mathrm{r}}=+12.4 \mathrm{~kJ} / \mathrm{mol}$ for the latter at $500{ }^{\circ} \mathrm{C}$ [29]. Thus, lowering reaction temperature increases the equilibrium conversion of $\mathrm{CO}$ and decreases that of $\mathrm{CH}_{4}$, which may be the reason for the $\mathrm{CO}$ conversion being much higher than the $\mathrm{CH}_{4}$ conversion in the reaction of $\mathrm{CO} / \mathrm{CH}_{4}$ mixture at low temperature $\left(500{ }^{\circ} \mathrm{C}\right)$ and low feed flowrates. Carbon deposits from nonoxidative $\mathrm{CH}_{4}$ dehydrogenation and/or $\mathrm{CO}$ disproportionation on oxide-supported metal catalysts can occur at relatively low temperatures to act as intermediates for both $\mathrm{CO}$ formation through carbon oxidation by $\mathrm{CO}_{2}$ and re-hydrogenation of surface carbon in dry gas reforming of $\mathrm{CO}$ and $\mathrm{CH}_{4}[19,20,29]$. Because of the reactions' reversibility and common intermediates and products of these nonoxidative reactions, the reaction rates and carbon product morphological properties are expected to depend on mutual influences between $\mathrm{CO}$ and $\mathrm{CH}_{4}$. Cofeeding $\mathrm{CH}_{4}$ can also influence the reaction thermodynamics and kinetics through its $\mathrm{H}_{2}$ product which, on the one hand, helps oxide reduction to create metallic components and, on the other hand, reduces the conversion rates and carbon yield by rehydrogenation of active carbon deposits [30]. The small amount of $\mathrm{H}_{2} \mathrm{O}$ generated by $\mathrm{CH}_{4}$ and $\mathrm{H}_{2}$ from reduction of metal oxides could also reduce the amorphous carbon coverage on the $\mathrm{Fe}$ catalysts to preserve surface activity for growing longer MWCNTs [31].

Figure 6 shows the characterizations of the carbon products from the $\mathrm{CO} / \mathrm{CH}_{4}$ mixture reaction. The SEM and TEM images in Figure $6 \mathrm{a}, \mathrm{b}$ reveal that the cleaned carbon products were MWCNTs without appreciable textures of graphitic particles or thick coatings. The MWCNT cleaning was done by sedimentation in ethanol solution for removal of the heavier glass fibers and large particles and subsequent dissolution of the exposed catalyst particles in $2 \mathrm{M} \mathrm{HCl}$ solution. The MWCNTs were found to have lengths in a range of $3-10 \mu \mathrm{m}$ and diameters in a range of $15-35 \mathrm{~nm}$. The high-resolution TEM images and interlayer spacing measurement in Figure $6 \mathrm{~b}$ or Figure S4a,b show CNT walls consisting of highly ordered 11-13 graphene layers at an interlayer spacing of $\sim 0.35 \mathrm{~nm}$, which form a uniform wall thickness of $4-5 \mathrm{~nm}$. The small $\mathrm{I}_{\mathrm{D}} / \mathrm{I}_{\mathrm{G}}$ ratio of $\sim 0.71$ in the Raman shift spectrum of Figure $6 \mathrm{c}$ also indicates a high crystallinity of the MWCNs, i.e., larger crystallite size and high-degree order of the constituting graphene layers in the nanotube wall [32]. The EDS spectrum in Figure 6d focused on the MWCNT tips and the inserted values from large area survey of the clean sample both showed negligible 
oxygen contents, suggesting the possible metallic form of iron nanoparticles enclosed in the MWCNTs due to further reduction of $\mathrm{Fe}^{2+}$ to $\mathrm{Fe}^{0}$ in the strongly reducing $\mathrm{CO} / \mathrm{CH}_{4}$ dry gas. The characteristic peaks of $\mathrm{Cr}$ were inappreciable, which may be a result of its extremely low content in the sample or removal by solid phase separation during the reduction process since $\mathrm{Cr}^{0}$ was not formed to alloy with $\mathrm{Fe}^{0}$. The full understanding of the chemical state and microstructure evolution of the FeCr catalyst during the reaction process is currently unclear and requires further investigation through in operando reaction measurements and in situ TEM and XPS examinations. The TGA/DTA measurement of the raw sample of MWCNTs, as shown in Figure S4c, indicated $\sim 46 \%$ MWCNTs due largely to the inclusion of glass fibers and catalyst particles of very large sizes. The relatively low temperature of carbon combustion, which is common in the literature for CNTs made by the CVD method, may be attributed to the exposed metal oxides in the raw sample, which could catalyze the CNT oxidation at low temperatures [33].

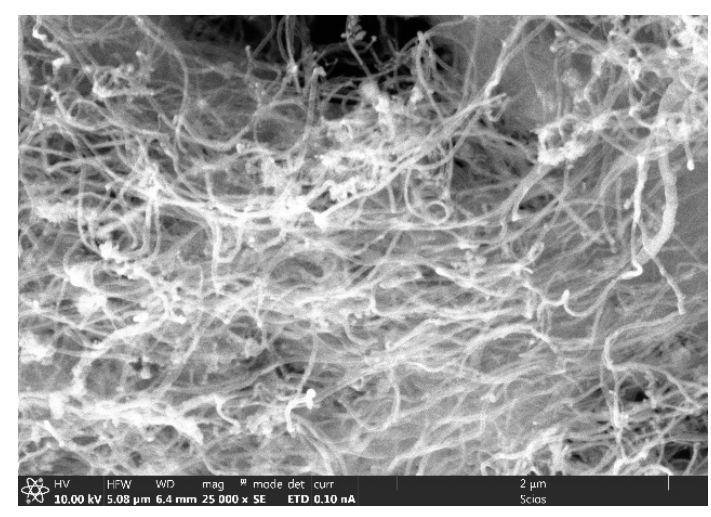

(a)

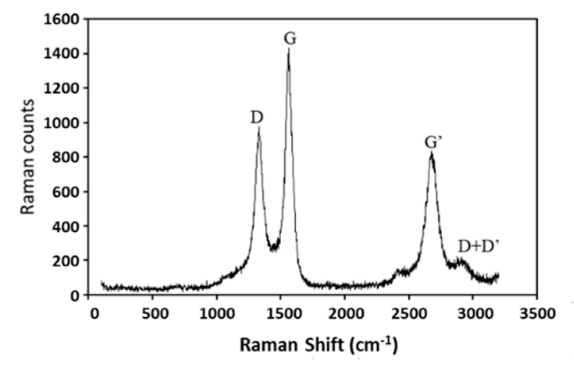

(c)

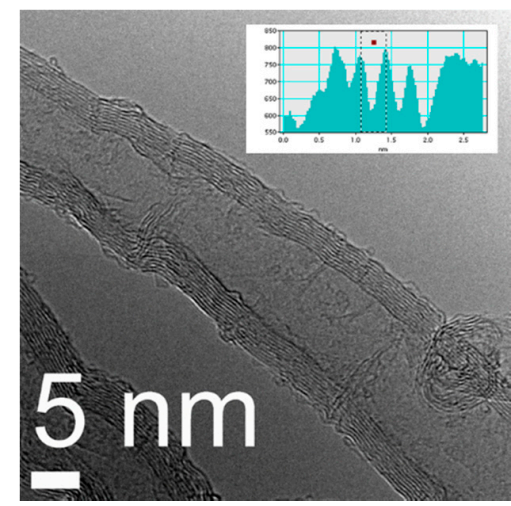

(b)

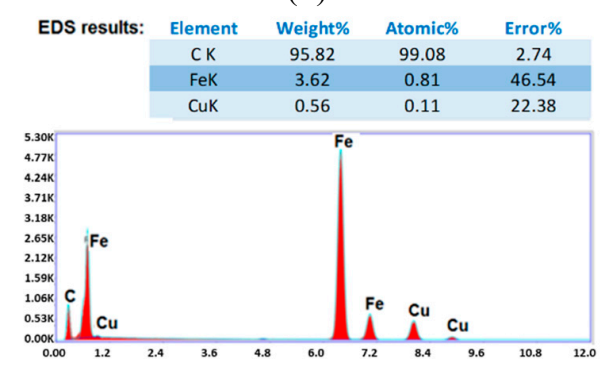

(d)

Figure 6. Characterizations of MWCNTs formed from the $\mathrm{CO} / \mathrm{CH}_{4}$ mixture: (a) SEM image, (b) TEM image showing typical MWCNT diameter and wall thickness, (c) Raman shift spectrum of the MWCNTs, and (d) EDS measurement focusing on MWCNT tips (insert survey over a large sample area).

In comparison with the observations on $\mathrm{CO}$ and $\mathrm{CH}_{4}$ single gas reactions, it can be inferred from the results of $\mathrm{CO} / \mathrm{CH}_{4}$ mixture reaction that synergistic effects between the $\mathrm{CH}_{4}$ and $\mathrm{CO}$ promoted MWCNT formation and enhanced the reaction rates. Literature studies have shown that the rates of $\mathrm{CNT}$ formation can be represented by semiempirical models that correlate the $\mathrm{CO}$ and $\mathrm{CH}_{4}$ reactions through kinetic and thermodynamic interactions of the common reactants/products [26]. Similar effects of $\mathrm{CO} / \mathrm{CH}_{4}$ mixture feeds on lowering temperature for carbon deposition and enhancing feed conversion as compared to the single gas feeds were also reported for the Mg-incorporated alumina-supported $\mathrm{Ni}$ nanoparticle catalyst, but the resultant MWCNs appeared to be of low crystallinity and dimensional uniformity [34]. However, fundamental understandings on the relationships between the produced carbon structure and the reaction conditions (including the $\mathrm{CO} / \mathrm{CH}_{4}$ feed composition as well as reaction temperature and pressure) and the catalyst type is currently challenging. In this study, the $\mathrm{FeCr}$ catalyst in the carbon product from $\mathrm{CO} / \mathrm{CH}_{4}$ mixture reaction was also examined by XPS to help understand the MWCNT formation process, which is discussed in the following section. 


\subsubsection{Effects of $\mathrm{H}_{2} \mathrm{~S}$ in Feed}

To investigate the influence of sulfur contents in the feed on the performance of the $\mathrm{FeCr}$ catalyst, reactions were performed for the $80 \mathrm{v} \% \mathrm{CO}+20 \mathrm{v} \% \mathrm{CH}_{4}$ mixtures containing 500 and $800 \mathrm{ppmv}$ of $\mathrm{H}_{2} \mathrm{~S}$, respectively. The rates of carbonization reactions decreased in the presence of $\mathrm{H}_{2} \mathrm{~S}$. The catalyst-packed tube was blocked by the carbon products in $3-4 \mathrm{~h}$ when the gas flowrate started to drop drastically after $\sim 2 \mathrm{~h}$ of reaction. Based on the gas product composition measured after the initial 60 min operation, the conversions of $\mathrm{CO}$ and $\mathrm{CH}_{4}$ were $\sim 6 \%$ and $<1 \%$, respectively, for the feed with $500 \mathrm{ppmv} \mathrm{H}_{2} \mathrm{~S}$, which decreased from those in reaction of the mixture without $\mathrm{H}_{2} \mathrm{~S}$. Figure 7 shows the SEM and TEM images and the Raman shift spectrum of the carbon products generated from the feed with 500 ppmv $\mathrm{H}_{2} \mathrm{~S}$, which was cleaned by two days of treatment in $2 \mathrm{M} \mathrm{HCl}$ solution under stirring. The carbon products were predominantly long and uniform MWCNTs of good crystallinity indicated by the small $\mathrm{I}_{\mathrm{D}} / \mathrm{I}_{\mathrm{G}}$ ratio $(\sim 0.80)$, which are very similar to those formed from the sulfur-free $\mathrm{CO} / \mathrm{CH}_{4}$ mixture. The TEM images in Figure $7 \mathrm{~b}$ indicate that the MWCNTs had an average diameter of $\sim 25 \mathrm{~nm}$ with 4-5 nm thick walls of highly aligned graphene layers. The EDS results of the MWCNTs after removing glass fibers and large particles but before cleaning by acid washing (Figure S5) confirmed the existence of significant sulfur content in the carbon/catalyst sample. However, the reaction of $\mathrm{CO} / \mathrm{CH}_{4}$ mixture with 800 ppmv $\mathrm{H}_{2} \mathrm{~S}$ resulted in carbon products mainly in the forms of thick graphitic coatings and particles with few MWCNTs (Figure S6). These morphological and structural properties of the MWCNTs are very similar for those produced by the feeds with and without the $500 \mathrm{ppmv}_{2} \mathrm{~S}$. This indicates that the $\mathrm{FeCr}$ catalyst has good sulfur resistance in catalyzing the MWCNT formation, but the reaction rates can be decreased by the presence of $\mathrm{H}_{2} \mathrm{~S}$. The apparently decreased reaction rates of the $\mathrm{H}_{2} \mathrm{~S}$-containing feeds may be a result of the loss of catalytically active sites due to the chemisorption of sulfide. It was found that $\mathrm{CO}$ chemisorption uptake on the $\mathrm{FeCr}$ catalyst declined significantly after being treated by $\mathrm{H}_{2} \mathrm{~S}$ at $500{ }^{\circ} \mathrm{C}$ (see Figure S7). The $\mathrm{FeCr}$ catalyst was also found to lose specific selectivity towards the MWCNT product for feeds with very high $\mathrm{H}_{2} \mathrm{~S}$ contents (e.g., 800 ppmv).

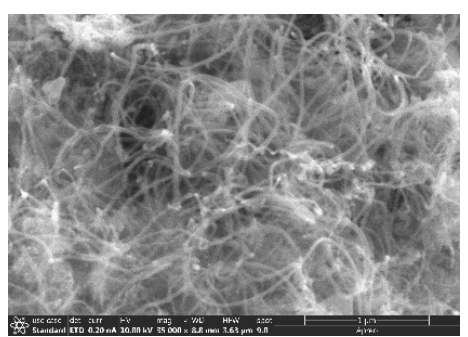

(a)

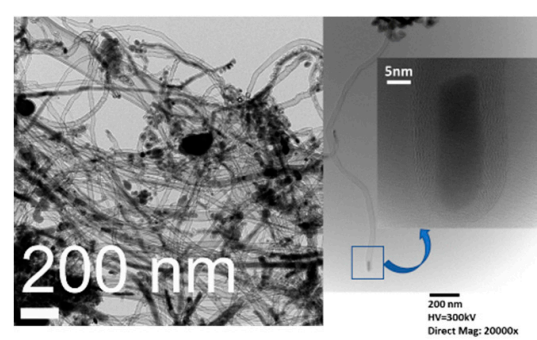

(b)

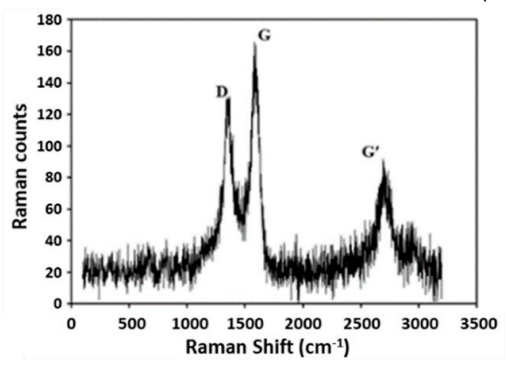

(c)

Figure 7. The MWCNTs produced by the FeCr catalyst at $500{ }^{\circ} \mathrm{C}$ and 1 bar from the $80 \% \mathrm{CO}+20 \% \mathrm{CH}_{4}$ mixture feed with 500 ppmv $\mathrm{H}_{2} \mathrm{~S}$ : (a) SEM image, (b) TEM images, and (c) Raman shift spectrum.

Compared to the MWCNTs formed on the FeCr catalysts in the HTP WGS MR, the MWCNTs obtained from the $\mathrm{CO} / \mathrm{CH}_{4}$ dry gas mixtures with or without $\mathrm{H}_{2} \mathrm{~S}$ impurity (500 ppmv) were apparently of larger length, better chirality and uniformity, and greater crystallinity. The XPS Fe $2 p$ spectra in Figure 8 a clearly show the presence of metallic iron $\left(\mathrm{Fe}^{0}\right)$ in the catalyst samples after reaction with the 
$\mathrm{CO} / \mathrm{CH}_{4}$ gas mixture with and without $\mathrm{H}_{2} \mathrm{~S}$ contents. The formation of metallic Fe component was not seen in the catalysts after HTP WGS membrane reaction (Figure 3). The further reduction of $\mathrm{Fe}^{2+}$ to $\mathrm{Fe}^{0}$ evidently occurred in the $\mathrm{CO} / \mathrm{CH}_{4}$ dry mixtures because the dry environment is more reductive than the steam-containing gas in the HTP WGS reaction [35]. The metallic iron nanoparticle or surface, which can form iron carbides and allow diffusion of carbon atoms to sustain the CNT growth, may be the main reason for the formation of highly crystalline MWCNTs from the $\mathrm{CO} / \mathrm{CH}_{4}$ dry mixture. However, the characteristic XPS peaks of iron carbides $\left(\mathrm{Fe}_{1-\mathrm{x}} \mathrm{C}_{\mathrm{x}}\right)$ around 285-295 and 710-722 eV overlap with the strong peaks of carbonaceous compounds in $\mathrm{C} 1 \mathrm{~s}$ and $\mathrm{Fe} 2 \mathrm{p}_{3 / 2}$ spectra, respectively [36]. Hence, the iron carbides would not be distinguishable due to the expected minimal mass amount, even if they existed. The XPS results in Figure $8 \mathrm{~b}$ indicate that further reduction of $\mathrm{Cr}^{3+}$ to $\mathrm{Cr}^{0}$ did not happen in the $\mathrm{CO} / \mathrm{CH}_{4}$ dry gases. These findings suggest that the $\mathrm{FeCr}$ catalyst formed metallic Fe nanoparticles supported on $\mathrm{Fe}^{3+/ 2+}$ and $\mathrm{Cr}^{6+/ 3+}$ oxides in which the oxide surface inhibited the migration and aggregation of metallic particles that may have, in turn, improved the MWCNT uniformity [37].

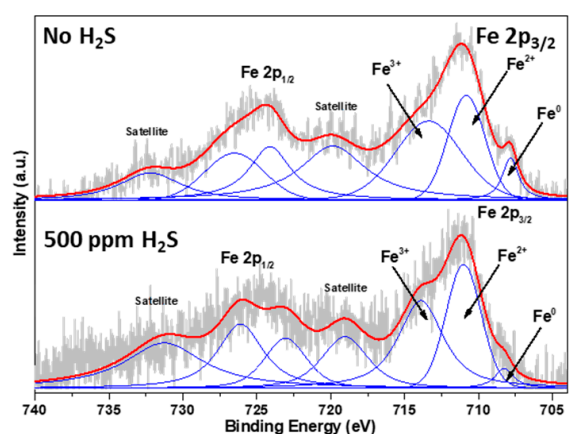

(a)

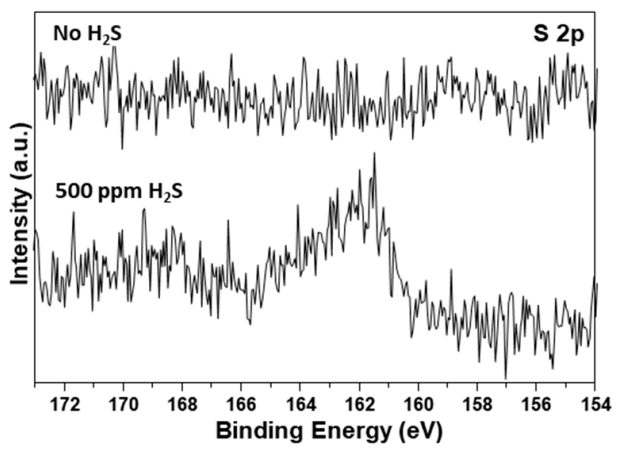

(c)

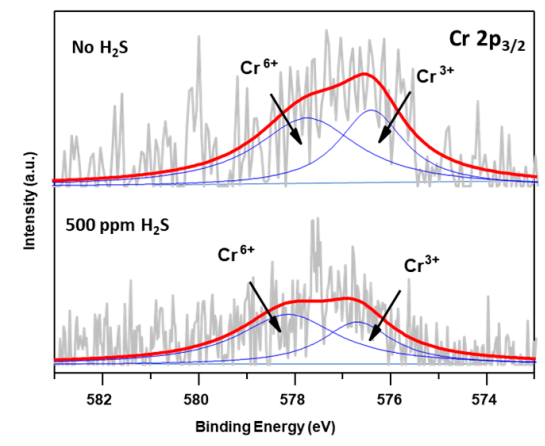

(b)

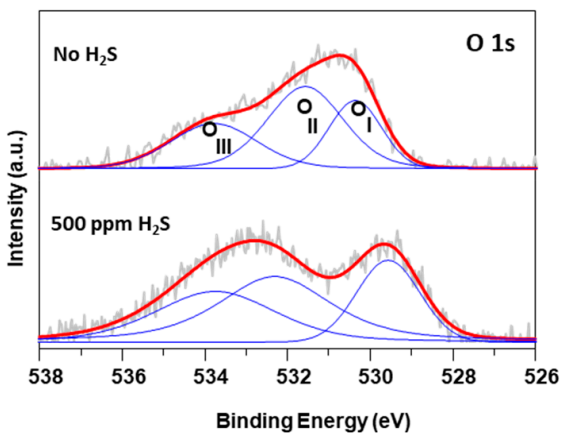

(d)

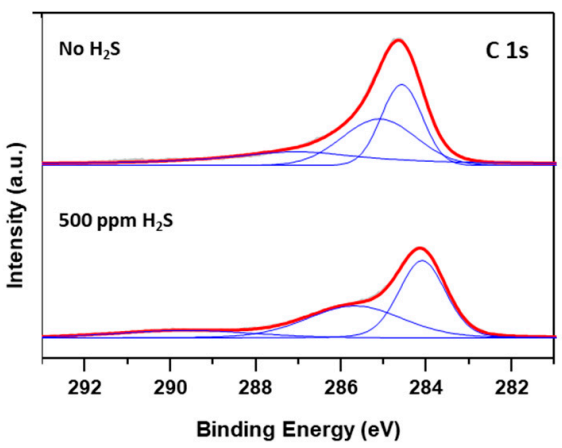

(e)

Figure 8. XPS spectra of the $\mathrm{FeCr}$ catalysts after reacting with the $\mathrm{CO} / \mathrm{CH}_{4}$ mixture with and without 500 ppmv $\mathrm{H}_{2} \mathrm{~S}$ : (a) Fe 2 $\mathrm{p}_{3 / 2}$ spectra, (b) Cr 2 $\mathrm{p}_{3 / 2}$ spectra, (c) O 1s spectra, (d) C 1s spectra, and (e) $\mathrm{S}$ 2 p spectra. 
The spectra of S 2p in Figure 8c clearly show the peak of $\mathrm{S}^{2-}$ at $158.5-165.7 \mathrm{eV}$ for the sample reacted with the 500 ppmv $\mathrm{H}_{2} \mathrm{~S}$ but not in the sample reacted with the sulfur-free gas. The sulfide ion $\left(\mathrm{S}^{2-}\right)$ is likely chemisorbed on the surfaces of the catalyst and/or MWCNT. The XPS spectra in Figure $8 \mathrm{~d}$,e indicate that the presence of trace sulfur in the catalyst surface did not cause notable changes to the types of chemical bonds formed by $\mathrm{CO}$ and $\mathrm{CH}_{4}$ reactions on the catalyst surfaces. These observations demonstrated that the existence of $\mathrm{H}_{2} \mathrm{~S}$ impurity in the $\mathrm{CO} / \mathrm{CH}_{4}$ feed gas with contents as high as 500 ppmv can introduce sulfur $\left(\mathrm{S}^{2-}\right)$ into the catalyst or carbon surfaces but not seriously influence the formation and morphological properties of the MWCNT products. However, the rates of CVD reactions are obviously slowed by the presence of the $\mathrm{H}_{2} \mathrm{~S}$ in gas phase, which may be chemisorbed on the catalyst surface to reduce the population of active catalytic sites. Extremely high contents of $\mathrm{H}_{2} \mathrm{~S}$ (e.g., 800 ppmv) can diminish the $\mathrm{FeCr}$ selectivity towards MWCNT products.

\section{Materials and Methods}

\subsection{Catalyst Preparation}

The nanocrystalline Cr-doped ferrite (FeCr) catalyst with an atomic ratio of $\mathrm{Fe}: \mathrm{Cr}=10: 1$ was prepared by the coprecipitation method following the procedure described in our earlier work [11]. This particular $\mathrm{Fe} / \mathrm{Cr}$ ratio was chosen because it was previously found to have the smallest crystallite size and exhibit high catalytic activity among several doped ferrite catalysts in high-temperature WGS reaction $[17,18]$. In brief, during catalyst synthesis, the calculated amounts of iron nitrate and chromium nitrate with $\mathrm{Fe}: \mathrm{Cr}$ atomic ratio of 10:1 were dissolved separately in DI water to form two solutions, which were subsequently mixed. A dilute aqueous ammonia solution was added to this mixed solution under stirring until precipitation was complete at a $\mathrm{pH}$ value of $\sim 9$. The resultant solid precipitates were recovered by filtration after overnight aging. The recovered solid was dried at $80^{\circ} \mathrm{C}$ for $12 \mathrm{~h}$ followed by a 3-hour calcination at $500{ }^{\circ} \mathrm{C}$ in nitrogen atmosphere using heating and cooling rates of $5{ }^{\circ} \mathrm{C} / \mathrm{min}$. The SEM image in Figure 9a shows that the as-synthesized FeCr oxide particles were agglomerated nanoparticles. The TEM image in Figure $9 \mathrm{~b}$ shows that the vast majority of primary particles had sizes of $15-25 \mathrm{~nm}$. The Fe:Cr atomic ratio of the FeCr catalyst was confirmed to be around $11 \pm 1.3$ by SEM-EDS measurement (Figure S7), which was in reasonable agreement with that of the precursor solution (Fe:Cr 10:1).

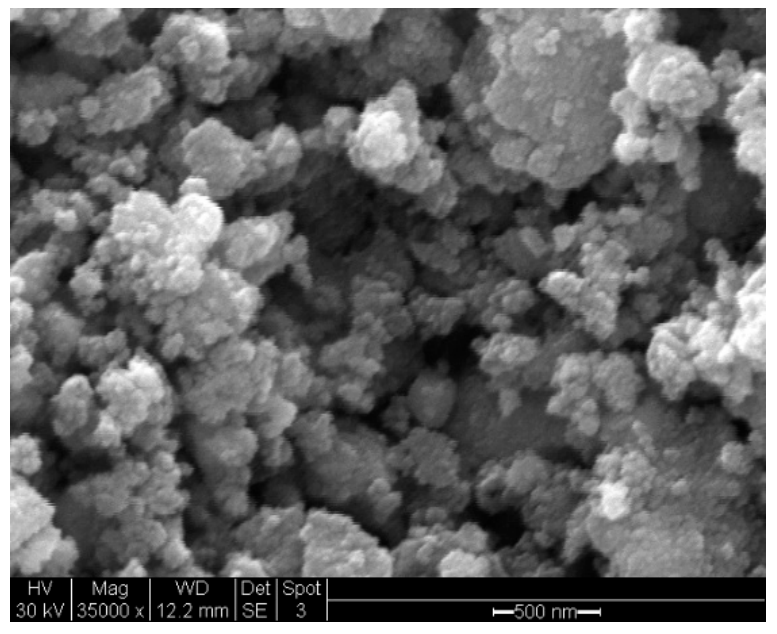

(a)

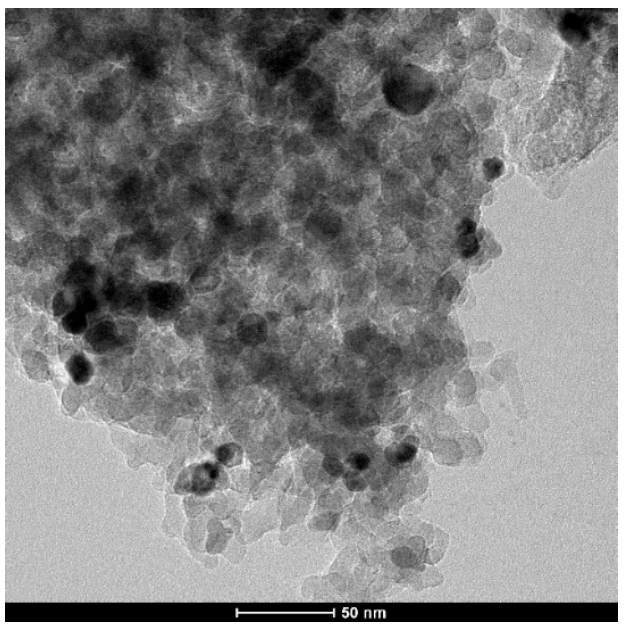

(b)

Figure 9. The as-synthesized FeCr catalyst: (a) SEM image and (b) TEM image.

\subsection{Membrane Fabrication}

The MFI-type zeolite membrane was synthesized on the outer surface of a commercially available porous $\alpha$-alumina tube (MPT Inc., Pittsburgh, PA, USA). The tube had an outer diameter (OD) of 
$0.57 \mathrm{~cm}$, an inner diameter (ID) of $0.37 \mathrm{~cm}$, and a total length of $10 \mathrm{~cm}$ with a $2.5 \mathrm{~cm}$ long glaze-sealed section in each end to give a $5 \mathrm{~cm}$ middle section coated with an active membrane area $A_{m}=8.95 \mathrm{~cm}^{2}$. The tubular zeolite membrane synthesis, modification, and characterization processes have been explained in our previous publications [5,38,39], and a brief description is provided together with the SEM images of the membrane in Figure S8 of the Supplementary Materials. The MFI zeolite membrane layer had a thickness of $\sim 7 \mu \mathrm{m}$. The zeolitic pore openings were reduced from the original diameter of 0.56 to $<0.36 \mathrm{~nm}$ by deposition of monosilica in the zeolite channels via the catalytic cracking deposition (CCD) method. The thus-narrowed zeolitic channels enable size exclusion effects to enhance the $\mathrm{H}_{2}$ permeation selectivity over $\mathrm{CO}$ and $\mathrm{CO}_{2}[39,40]$. The modified zeolite membrane used in this work had a $\mathrm{H}_{2}$ permeance $\left(P_{m, H 2}\right)$ of $\sim 1.02 \times 10^{-7} \mathrm{~mol} / \mathrm{s} \cdot \mathrm{m}^{2}$.Pa with $\mathrm{H}_{2}$ permeation selectivity over $\mathrm{CO}$ $\left(\alpha_{\mathrm{H} 2 / \mathrm{CO}}\right), \mathrm{CO}_{2}\left(\alpha_{\mathrm{H} 2 / \mathrm{CO} 2}\right)$ and $\mathrm{H}_{2} \mathrm{O}\left(\alpha_{\mathrm{H} 2 / \mathrm{H} 2 \mathrm{O}}\right)$ of $33 \pm 5$ and $25 \pm 3$ and $5 \pm 2$ respectively, at $500{ }^{\circ} \mathrm{C}$. The gas permeance is defined as

$$
P_{m, i}=\frac{Q_{i}}{A_{m} \cdot \Delta P_{i}}
$$

where $Q_{i}\left(\mathrm{~mol} / \mathrm{s} ; i=H_{2}, \mathrm{CO}, \mathrm{CO}_{2}, \mathrm{H}_{2} \mathrm{O}\right)$ is the flowrate of gas $i$ through the membrane and $\Delta P_{i}=P_{i, f}-P_{i, p}$, where $P_{i, f}$ and $P_{i, p}$ are the gas partial pressures in the feed and permeate side, respectively. The $\mathrm{H}_{2}$ separation selectivity over gas $i\left(\alpha_{H 2 / i}\right)$ measured by mixture gas permeation is given by

$$
\alpha_{H 2 / i}=\frac{\left(y_{H 2} / y_{i}\right)_{p}}{\left(y_{H 2} / y_{i}\right)_{f}}
$$

where $y_{\mathrm{H} 2}$ and $y_{i}$ are gas mole fractions and subscripts $p$ and $f$ denote permeate and feed, respectively.

\subsection{Reactors and Operations}

The WGS reaction in the zeolite MR was carried out at $500{ }^{\circ} \mathrm{C}$ to study the $\mathrm{FeCr}$ catalyst activities for simultaneously producing $\mathrm{H}_{2}$ and MWCNTs. The MR-which is a stainless steel module with the tube membrane mounted in the tube-in-shell structure-and the gas streams were in countercurrent crossflow configuration, as shown in Figure 10. The membrane tube was sealed in the MR by graphite gaskets. A total amount of $\sim 0.7 \mathrm{~g} \mathrm{FeCr}$ catalyst particles (packing density $\sim 2.9 \mathrm{~g} / \mathrm{cm}^{3}$ ) were mixed with quartz wool and packed inside the tube as schematically illustrated by the insert in Figure 10. The catalyst bed started approximately $0.5 \mathrm{~cm}$ after the tube entrance, i.e., $\sim 2.0 \mathrm{~cm}$ before the active membrane section and was evenly distributed along the entire membrane section. The MR was installed in a reaction testing system schematically shown in Figure 10. The pre-membrane catalyst bed, which converts a significant amount of $\mathrm{CO}$ before entering the membrane section, is necessary for membranes of moderate $\alpha_{\mathrm{H} 2 / \mathrm{CO}}$ to lower the reaction side $\mathrm{CO}$ partial pressure at the beginning of the membrane for preventing excessive permeation of unreacted CO. The WGS and dry gas reactions are exothermic overall, which may cause temperature increases to induce instability and affect reactor performance [41]. However, the small ceramic tube reactor, because of the large stainless steel housing and minimal amount of catalyst used, was able to stabilize the operation, with the exiting gas temperature increases being limited to $<10{ }^{\circ} \mathrm{C}$. 


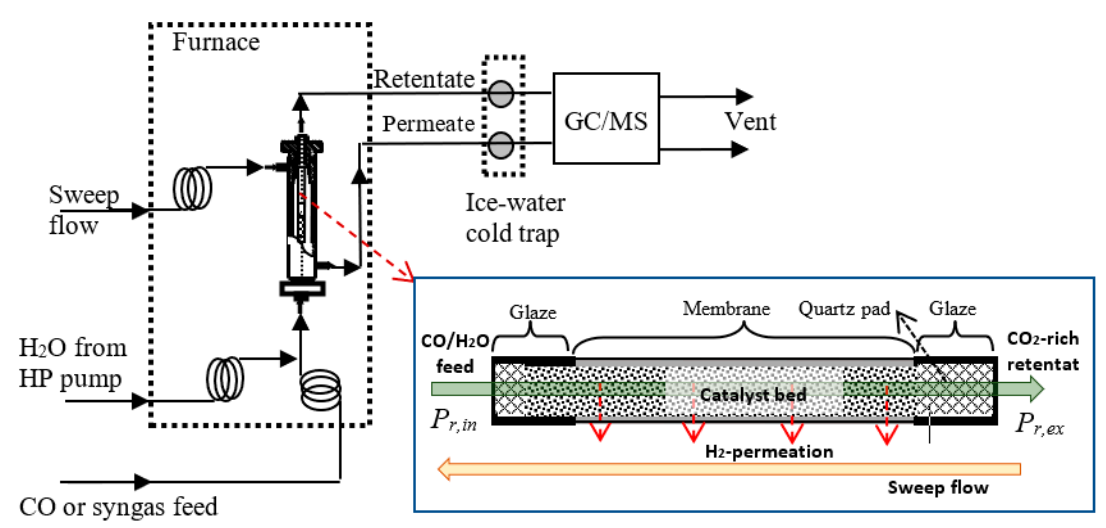

Figure 10. Schematic diagram of the WGS MR reaction system with an insert depicting the catalyst packing structure and countercurrent gas flow configuration.

The catalyst was activated after being packed in the MR by partial reduction at $400{ }^{\circ} \mathrm{C}$ for $4 \mathrm{~h}$ in a process gas flow containing $33.3 \% \mathrm{CO}, 25.0 \% \mathrm{CO}_{2}, 25.0 \% \mathrm{H}_{2}$, and $16.7 \% \mathrm{H}_{2} \mathrm{O}$ [4]. The WGS membrane reaction was performed at $500{ }^{\circ} \mathrm{C}$ and retentate exit pressures $P_{\text {r.ex }}$ varying from $\sim 2$ to $\sim 20$ bar. The feed stream with an $R_{S / C O}$ of 3.5 was fed at GHSV of $7500 \mathrm{~h}^{-1}$. The permeate side was swept by $\mathrm{N}_{2}$ at atmospheric pressure. The countercurrent $\mathrm{N}_{2}$ sweep flow makes it possible to achieve a near-zero $\mathrm{H}_{2}$ mole fraction $y_{\mathrm{H} 2, r}$ at the retentate exit (where $P_{\mathrm{H} 2, r}=y_{\mathrm{H} 2, r} P_{r, e x} \rightarrow 0 \mathrm{~Pa}$ ) that is required for approaching complete $\mathrm{CO}$ conversion for the reversible WGS reaction. These reaction conditions were chosen based on our previous experimental and modeling findings on MRs consisting zeolite membranes and doped ferrite catalysts of separation and catalytic properties comparable to this work [4,5]. The GHSV is defined by [42]

$$
G H S V=\frac{\sum v_{f}^{i}}{m_{\text {cat }} / \rho_{\text {cat }}}
$$

where $v_{f}^{i}$ is the STP volumetric flowrate of component $i\left(=\mathrm{CO}, \mathrm{CO}_{2}, \mathrm{H}_{2}, \mathrm{H}_{2} \mathrm{O}\right)$ and $m_{\text {cat }}$ and $\rho_{\text {cat }}$ are the total load $(\mathrm{g})$ and packing density $\left(\mathrm{g} / \mathrm{cm}^{3}\right)$ of the catalyst, respectively. The pure $\mathrm{N}_{2}$ sweep was maintained at a flowrate of $25 \mathrm{~cm}^{3}(\mathrm{STP}) / \mathrm{min}$. Both the retentate and permeate streams were analyzed by the online GC. The MR CO conversion $\chi_{\mathrm{CO}}$ and $\mathrm{H}_{2}$ recovery $\left(R_{\mathrm{H} 2}\right)$ in permeate are defined as

$$
\begin{gathered}
\chi_{\mathrm{CO}}=1-\frac{F_{\mathrm{CO}}^{\text {out }}}{F_{\mathrm{CO}}^{\text {in }}} \\
R_{H 2}=\frac{\text { Moles of } \mathrm{H}_{2} \text { in permeate }}{\text { Total moles of } \mathrm{H}_{2} \text { generated }}
\end{gathered}
$$

where $F_{C O}^{\text {in }}$ and $F_{C O}^{o u t}$ are the $\mathrm{CO}$ flowrates entering and exiting the MR, respectively, and $F_{C O}^{o u t}$ accounts for $\mathrm{CO}$ flowrates in both retentate and permeate sides.

In the experiments of dry gas reaction on the $\mathrm{FeCr}$ catalyst, a conventional tubular packed bed reactor (PBR) was employed. The PBR was made of the same $10 \mathrm{~cm}$ long alumina tube by sealing the entire tube outer surface by the gas-impermeable glaze coating and a total amount of $\sim 0.5 \mathrm{~g} \mathrm{FeCr}$ catalyst was packed in the same way as was done in the tubular MR. However, less quartz wool was used to get a more loosely packed bed in the PBR so that that the carbon products can grow in more space without blocking the tube. While the gas products were monitored by the online GC-MS, the solid products including carbon materials and reacted catalyst particles were retrieved and examined by ex situ characterizations. The morphology and dimensions of the solid materials were observed by SEM and TEM, and their elemental compositions were examined by the EDS technique. The catalysts at different processing stages were analyzed by XPS to study the metal oxidation state changes with 
reaction conditions. The XPS experiments were performed on a Thermo VG Scientific spectrometer using $\mathrm{Al} \mathrm{K} \alpha(1486.7 \mathrm{eV})$ radiation as the excitation source at room temperature. The pressure of the catalyst sample chamber was maintained below $10^{-8} \mathrm{~Pa}$ to avoid a large amount of noise in the spectra from contaminants. The obtained binding energies were adjusted by referencing the spectra to the carbon (C 1s) peak at $284.6 \mathrm{eV}$. The MWCNTs was also characterized by Raman shift spectroscopy for assessment of the graphitic phase and crystallinity and by thermogravimetric analysis (TGA) to estimate the amount of carbon product.

\section{Conclusions and Perspectives}

The nanocrystalline $\mathrm{FeCr}$ catalyst with an atomic ratio of $\mathrm{Fe} / \mathrm{Cr}=10: 1$ was capable of coproducing $\mathrm{H}_{2}$ and MWCNTs with near-complete CO conversion ( $\chi_{\mathrm{CO}}>99.5 \%$ ) by WGS reaction at $500{ }^{\circ} \mathrm{C}$ and 20 bar in a $\mathrm{H}_{2}$-permselective MR. The MWCNT formation in the HTP WGS MR apparently involved catalyst surface carbonizations of both $\mathrm{CO}$ and $\mathrm{CH}_{4}$, with the latter being a major byproduct of WGS reaction favored at high pressures. Extended experiments on the dry gas reactions indicated synergistic effects of $\mathrm{CO}$ and $\mathrm{CH}_{4}$ carbonization reactions, which promoted the rapid growth of uniform and highly crystalline MWCNTs at atmospheric pressure and $500^{\circ} \mathrm{C}$, which is a temperature much lower than those for CVD synthesis of CNTs from either $\mathrm{CO}$ or $\mathrm{CH}_{4}$ on metallic nanoparticles. The MWCNTs formed from the $\mathrm{CO} / \mathrm{CH}_{4}$ dry mixture were of higher crystallinity and dimensional uniformity and greater length than those from the HTP WGS membrane reactions apparently because of the further reduction of $\mathrm{Fe}^{2+}$ to $\mathrm{Fe}^{0}$ in the dry gas conditions that was not observed in the WGS reaction environments. The $\mathrm{FeCr}$ catalyst also exhibited high tolerance to $\mathrm{H}_{2} \mathrm{~S}$ impurity in the $\mathrm{CO} / \mathrm{CH}_{4}$ mixture feed during the CVD synthesis of MWCNTs. The good sulfur resistance of the catalyst is practically desirable for the potential utilization of biogas and coal-derived syngas for production of high-value CNTs. Further in operando reaction kinetic studies and in situ TEM and XPS observations of the catalyst and carbon structural and chemical state evolutions are needed for understanding the reaction mechanisms to guide catalyst improvement and reaction process optimization.

Supplementary Materials: The following are available online at http://www.mdpi.com/2073-4344/10/8/927/s1. Membrane fabrication method description; Figure S1: $\mathrm{CO}$ conversion and $\mathrm{CH}_{4}$ content changes during the WGS reaction in the zeolite $\mathrm{MR}$ at $500{ }^{\circ} \mathrm{C}$ as functions of time and pressure: (a) GHSV $=15,000 \mathrm{~h}^{-1}$ and $R_{S / C O}=3.5$, (b) GHSV $=30,000 \mathrm{~h}^{-1}$ and $R_{S / C O}=3.5$, (c) GHSV $=15,000 \mathrm{~h}^{-1}$ and $R_{S / C O}=1.5$; Figure S2: SEM and TEM images of the MWCNT tips growing on catalyst nanoparticles of various sizes during HTP WGS reaction in the zeolite MR: (a) SEM image showing MWCNTs of different diameters, (b) TEM image showing catalyst particles in MWCNTs ends, (c) a growing tip on a catalyst particle of $\sim 10 \mathrm{~nm}$ in size, (d)-(f) MWCNT tips on catalyst particles of different sizes and shapes; Figure S3: Results of pure CO feed reaction at 1.5 bar: (a) CO conversion as a function of time and reaction pressure, (b) and (c) the SEM and EDS results of the solid products, and (d) and (e) TEM image showing graphitic carbon coating on catalyst and Raman shift spectrum of the carbon product; Figure S4: TEM and TGA examinations of the MWCNTs produced from a gas mixture of $80 \mathrm{v} . \% \mathrm{CO}+20 \mathrm{v} . \% \mathrm{CH}_{4}$ on the $\mathrm{FeCr}$ nanoparticle catalyst when reacting at $500{ }^{\circ} \mathrm{C}$ and ambient pressure: (a) TEM image showing the uniformity of the long MWCNTs, (b) HR TEM image of a MWCNT tip containing a catalyst nanoparticle that appeared to be metallic Fe based on the electron diffraction pattern and EDS data, and (c) TGA/DTA results of the raw products containing MWCNTs, large catalyst particles, and supporting glass fibers; Figure S5: Results of SEM-EDS analysis for the MWCNT/catalyst product from reaction of the $\mathrm{CO} / \mathrm{CH}_{4}$ mixture $\left(80 \% \mathrm{CO}+20 \% \mathrm{CH}_{4}\right)$ containing $500 \mathrm{ppmv}$ $\mathrm{H}_{2} \mathrm{~S}$; Figure S6: (a) The SEM image of carbon product on the $\mathrm{FeCr}$ catalyst generated at $500{ }^{\circ} \mathrm{C}$ and 1 bar from the feed of $80 \% \mathrm{CO}+20 \% \mathrm{CH}_{4}$ with $800 \mathrm{ppmv} \mathrm{H}_{2} \mathrm{~S}$, (b) Raman shift spectrum of the carbon product, and (c) results of $\mathrm{CO}$ chemisorption on fresh $\mathrm{FeCr}$ catalyst and on $\mathrm{FeCr}$ catalyst treated by $1000 \mathrm{ppmv} \mathrm{H}_{2} \mathrm{~S}$ in $\mathrm{N}_{2}$ gas at $500{ }^{\circ} \mathrm{C}$ for 5 h; Figure S7: The EDS survey of the FeCr catalyst indicating a Fe:Cr atomic ratio of $11 \pm 1.3$ that agrees with the ratio in synthesis precursor ( 10:1); Figure S8: The SEM images of the MFI-type zeolite membrane synthesized on the outer surface of the alumina tube: (a) fractured cross-section and (b) surface.

Author Contributions: Conceptualization, J.D.; Data curation, X.S. and A.A.; Formal analysis, D.D., N.T.A. and J.D.; Funding acquisition, J.D.; Investigation, X.S., A.A. and D.D.; Resources, V.S. and P.G.S.; Supervision, N.T.A., V.S., P.G.S. and J.D.; Validation, V.S.; Writing—original draft, X.S.; Writing-review and editing, J.D. All authors have read and agreed to the published version of the manuscript.

Funding: This research was financially supported by the Development Service Agency of Ohio through the Ohio Coal Research and Development program (Grant no. OOECDO-D-17-13) and the U.S. Department of Energy/NETL through Grant no. DE-FE0026435. The porous alumina tube supports were provided by Media and Processes Technology Inc., Pittsburgh, USA. 
Conflicts of Interest: The authors declare no conflicts of interest.

\section{References}

1. Lin, Y.S. Inorganic Membranes for Process Intensification: Challenges and Perspective. Ind. Eng. Chem. Res. 2018, 58, 5787-5796. [CrossRef]

2. Damma, D.; Smirniotis, P.G. Recent advances in iron-based high-temperature water-gas shift catalysis for hydrogen production. Curr. Opin. Chem. Eng. 2018, 21, 103-110. [CrossRef]

3. Kim, S.J.; Xu, Z.; Reddy, G.K.; Dong, J.; Smirniotis, P. Effect of Pressure on High Temperature Water Gas Shift Reaction in Microporous Zeolite Membrane Reactor. Ind. Eng. Chem. Res. 2012, 51, 1364-1375. [CrossRef]

4. Kim, S.J.; Yang, S.; Reddy, G.K.; Dong, J.; Smirniotis, P. Zeolite membrane reactor for high temperature water gas shift reaction: Experimental and simulation studies. Energy Fuels 2013, 27, 4471-4480. [CrossRef]

5. Arvanitis, A.; Sun, X.; Yang, S.; Damma, D.; Smirniotis, P.; Dong, J. Approaching Complete CO Conversion and Total $\mathrm{H}_{2}$ Recovery for Water Gas Shift Reaction in a High-Temperature and High-Pressure Zeolite Membrane Reactor. J. Membr. Sci. 2018, 549, 575-580. [CrossRef]

6. LeValley, T.L.; Richard, A.R.; Fan, M. The progress in water gas shift and steam reforming hydrogen production technologies-A review. Int. J. Hydrog. Energy 2014, 39, 16983-17000. [CrossRef]

7. Nikolaev, P.; Bronikowski, M.J.; Bradley, R.K.; Rohmund, F.; Colbert, D.T.; Smith, K.A.; Smalley, R.E. Gas-phase catalytic growth of single-walled carbon nanotubes from carbon monoxide. Chem. Phys. Lett. 1999, 313, 91-97. [CrossRef]

8. Selbmann, D.; Bendjemil, B.; Leonhardt, A.; Pichler, T.; Täschner, C.; Ritschel, M. A parametric study of the synthesis and purification of single-walled carbon nanotubes using the high-pressure carbon monoxide process. Appl. Phys. A 2008, 90, 637-643. [CrossRef]

9. Ashik, U.P.M.; Daud, W.W.; Abbas, H.F. Production of greenhouse gas free hydrogen by thermocatalytic decomposition of methane-A review. Renew. Sustain. Energy Rev. 2015, 44, 221-256. [CrossRef]

10. Tang, L.; Yamaguchi, D.; Burke, N.; Trimm, D.; Chiang, K. Methane decomposition over ceria modified iron catalysts. Catal. Commun. 2010, 11, 1215-1219. [CrossRef]

11. Gunugunuri, K.R.; Kim, S.J.; Dong, J.; Jasinski, J.B.; Smirniotis, P. Long-term WGS stability of Fe/Ce and $\mathrm{Fe} / \mathrm{Ce} / \mathrm{Cr}$ catalysts at high and low steam to CO ratios-XPS and Mössbauer spectroscopic study. Appl. Catal. A Gen. 2012, 415, 101-110.

12. Lee, S.H.; Park, J.P.; Kim, H.R.; Lee, J.G.; Hong, K.H. Synthesis of high-quality carbon nanotube fibers by controlling the effects of sulfur on the catalyst agglomeration during the direct spinning process. RSC Adv. 2015, 5, 41894-41900. [CrossRef]

13. Moon, S.Y.; Kang, I.J.; Kim, S.M.; Kim, W.S. Influence of the Sulfur Content Catalyst on the Packing Density of Carbon Nanotube Forests. Nanomaterials 2019, 9, 889. [CrossRef]

14. Wang, H.; Wei, L.; Ren, F.; Wang, Q.; Pfefferle, L.D.; Haller, G.L.; Chen, Y. Chiral-Selective $\mathrm{CoSO}_{4} / \mathrm{SiO}_{2}$ Catalyst for Single-Walled Carbon Nanotube Growth. ACS Nano 2013, 7, 614-626. [CrossRef]

15. Wang, H.; Ren, F.; Liu, C.; Si, R.; Yu, D.; Pfefferle, L.D.; Haller, G.L.; Chen, Y. $\mathrm{CoSO}_{4} / \mathrm{SiO}_{2}$ catalyst for selective synthesis of single-walled carbon nanotubes: Effect of catalyst calcination. J. Catal. 2013, 300, 91-101. [CrossRef]

16. Wang, H.; Yang, L.; Sui, X.; Karhan, H.E.; Wang, X.; Chen, Y. Selective synthesis of single walled carbon nanotubes on metal (iron, nickel or cobalt) sulfate-based catalysts. Carbon 2018, 129, 128-136. [CrossRef]

17. Rhodes, C.; Williams, P.B.; King, F.; Hutchings, G.J. Promotion of $\mathrm{Fe}_{3} \mathrm{O}_{4} / \mathrm{Cr}_{2} \mathrm{O}_{3}$ high temperature water gas shift catalyst. Catal. Commun. 2002, 3, 381-384. [CrossRef]

18. Damma, D.; Smirniotis, P.G. Effects of the Ce and Cr Contents in Fe-Ce-Cr Ferrite Spinels on the High-Temperature Water-Gas Shift Reaction. Ind. Eng. Chem. Res. 2017, 56, 1772-1781.

19. Choudhary, T.V.; Aksoylu, E.; Goodman, D.W. Nonoxidative Activation of Methane. Catal. Rev. 2003, 45, 151-203. [CrossRef]

20. Gu, X.; Zhang, J.; Dong, J.; Nenoff, T.M. A Platinum-Cobalt-Loaded NaY Zeolite Membrane for Nonoxidative Conversion of Methane to Higher Hydrocarbons and Hydrogen. Catal. Lett. 2005, 102, 9-13. [CrossRef]

21. Robertson, J. Heterogeneous catalysis model of growth mechanisms of carbon nanotubes, graphene and silicon nanowires. J. Mater. Chem. 2012, 22, 19858-19862. [CrossRef] 
22. Hofmann, S.; Sharma, R.; Ducati, C.; Du, G.; Mattevi, C.; Cepek, C.; Cantoro, M.; Pisana, S.; Parvez, A.; Cervantes-Sodi, F.; et al. In situ Observations of Catalyst Dynamics during Surface-Bound Carbon Nanotube Nucleation. Nano Lett. 2007, 7, 602-608. [CrossRef] [PubMed]

23. Rönsch, S.; Schneider, J.; Matthischke, S.; Schlüter, M.; Götz, M.; Lefebvre, J.; Prabhakaran, P.; Bajohr, S. Review on methanation-From fundamentals to current projects. Fuel 2016, 166, 276-296. [CrossRef]

24. Chen, C.J.; Back, M.H.; Back, B.A. The Thermal Decomposition of Methane. I. Kinetics of the Primary Decomposition to $\mathrm{C}_{2} \mathrm{H}_{6}+\mathrm{H}_{2}$; Rate Constant for the Homogeneous Unimolecular Dissociation of Methane and its Pressure Dependence. Can. J. Chem. 1975, 53, 3580-3590. [CrossRef]

25. Pinilla, J.L.; Utrilla, R.; Lázaro, M.J.; Moliner, R.; Suelves, I.; García, A.B. Ni- and Fe-based catalysts for hydrogen and carbon nanofilament production by catalytic decomposition of methane in a rotary bed reactor. Fuel Process. Technol. 2011, 92, 1480-1488. [CrossRef]

26. Moothi, K.; Simate, G.S.; Falcon, R.; Iyuke, S.E.; Meyyappan, M. Carbon Nanotube Synthesis Using Coal Pyrolysis. Langmuir 2015, 31, 9464-9472. [CrossRef]

27. Jia, Z.; Kou, K.; Qin, M.; Wu, H.; Puleo, F.; Liotta, L.F. Controllable and Large-Scale Synthesis of Carbon Nanostructures: A Review on Bamboo-Like Nanotubes. Catalysts 2017, 7, 256. [CrossRef]

28. Shandakov, S.D.; Kosobutsky, A.V.; Rybakov, M.S.; Sevostyanov, O.G.; Russakov, D.M.; Lomakin, M.V.; Vershinina, A.I.; Chirkova, I.M. Effect of gaseous and condensate products of ethanol decomposition on aerosol CVD synthesis of single-walled carbon nanotubes. Carbon 2018, 126, 522-531. [CrossRef]

29. Gili, A.; Schlicker, L.; Bekheet, M.F.; Görke, O.; Penner, S.; Grünbacher, M.; Götsch, T.; Littlewood, P.; Marks, T.J.; Stair, P.C.; et al. Surface Carbon as a Reactive Intermediate in Dry Reforming of Methane to Syngas on a 5\% Ni/MnO Catalyst. ACS Catal. 2018, 8, 8739-8750. [CrossRef]

30. Anoshkin, I.V.; Nasibulin, A.G.; Tian, Y.; Liu, B.; Jiang, H.; Kauppinen, E.I. Hybrid carbon source for single-walled carbon nanotube synthesis by aerosol CVD method. Carbon 2014, 78, 130-136. [CrossRef]

31. Hata, K.; Futaba, D.N.; Mizuno, K.; Namai, T.; Yumura, M.; Iijima, S. Water-Assisted Highly Efficient Synthesis of Impurity-Free Single-Walled Carbon Nanotubes. Science 2004, 306, 1362-1364. [CrossRef] [PubMed]

32. Pumera, M.; Iwai, H. Multicomponent Metallic Impurities and Their Influence upon the Electrochemistry of Carbon Nanotubes. J. Phys. Chem. C 2009, 113, 4401-4405. [CrossRef]

33. Srikanth, I.; Padmavathi, N.; Prasad, P.S.R.; Ghosal, P.; Jaini, R.K.; Subrahmanya, C. Effect of high-temperature heat treatment duration on the purity and microstructure of MWCNTs. Bull. Mater. Sci. 2016, 39, 41-46. [CrossRef]

34. Zhang, B.; Piao, G.; Zhang, J.; Bub, C.; Xie, H.; Wu, B.; Kobayashi, N. Synthesis of carbon nanotubes from conventional biomass-based gasification Gas. Fuel Process. Technol. 2018, 180, 105-113. [CrossRef]

35. Kuznetsov, B.N.; Chudinov, M.G.; Alekseev, A.M.; Yakerson, V.I. Effect of reaction mixture, oxidative and reductive media on element distribution and iron valence state on the surface of a medium-temperature iron-chromium catalyst. Kinet. Catal. 1996, 37, 846-849.

36. Furlan, A.; Jansson, U.; Lu, J.; Hultman, L.; Magnuson, M. Structure and bonding in amorphous iron carbide thin films. J. Phys. Condens. Matter 2015, 27, 045002. [CrossRef]

37. Da Cunha, T.H.R.; De Oliveira, S.; Martins, I.L.; Geraldo, V.; Miquita, D.; Ramos, S.L.M.; Lacerda, R.G.; Ladeira, L.O. High-yield synthesis of bundles of double- and triple-walled carbon nanotubes on aluminum flakes. Carbon 2018, 133, 53-61. [CrossRef]

38. Gu, X.; Tang, Z.; Dong, J. On-Stream Modification of MFI Zeolite Membranes for Enhancing Hydrogen Separation at High Temperature. Microporous Mesoporous Mater. 2008, 111, 441-448. [CrossRef]

39. Tang, Z.; Nenoff, T.M.; Dong, J. Internal Surface Modification of MFI-Type Zeolite Membranes for High Selectivity and High Flux for Hydrogen. Langmuir 2009, 25, 4848-4852. [CrossRef]

40. Masuda, T.; Fukumoto, N.; Kitamura, M. Modification of pore size of MFI-type zeolite by catalytic cracking of silane and application to preparation of $\mathrm{H}_{2}$-separating zeolite membrane. Microporous Mesoporous Mater. 2001, 48, 239-245. [CrossRef]

41. Palma, V.; Ruocco, C.; Cortese, M.; Martino, M. Recent Advances in Structured Catalysts Preparation and Use in Water-Gas Shift Reaction. Catalysts 2019, 9, 991. [CrossRef]

42. Haber, J. Manual on Catalyst Characterization. Pure Appl. Chem. 1991, 63, 1227-1246. [CrossRef] 